Review Article

\title{
Interplay between Mitochondrial Metabolism and Cellular Redox State Dictates Cancer Cell Survival
}

\author{
Brittney Joy-Anne Foo, ${ }^{1}$ Jie Qing Eu, ${ }^{1,2}$ Jayshree L. Hirpara, ${ }^{2}$ and Shazib Pervaiz $\mathbb{1}$ 1,3,4,5,6,7 \\ ${ }^{1}$ Department of Physiology, Yong Loo Lin School of Medicine, National University of Singapore (NUS), Singapore, Singapore \\ ${ }^{2}$ Cancer Science Institute, NUS, Singapore, Singapore \\ ${ }^{3}$ NUS Center for Cancer Research (N2CR), Yong Loo Lin School of Medicine, NUS, Singapore, Singapore \\ ${ }^{4}$ NUS Medicine Healthy Longevity Program, Yong Loo Lin School of Medicine, NUS, Singapore, Singapore \\ ${ }^{5}$ Integrative Sciences and Engineering Program, NUS Graduate School, NUS, Singapore, Singapore \\ ${ }^{6}$ National University Cancer Institute, National University Health System, Singapore, Singapore \\ ${ }^{7}$ Faculté de Médicine, Université de Paris, Paris, France \\ Correspondence should be addressed to Shazib Pervaiz; phssp@nus.edu.sg
}

Received 22 August 2021; Revised 30 September 2021; Accepted 4 October 2021; Published 3 November 2021

Academic Editor: Qiang Tong

Copyright ( 2021 Brittney Joy-Anne Foo et al. This is an open access article distributed under the Creative Commons Attribution License, which permits unrestricted use, distribution, and reproduction in any medium, provided the original work is properly cited.

\begin{abstract}
Mitochondria are the main powerhouse of the cell, generating ATP through the tricarboxylic acid cycle (TCA) and oxidative phosphorylation (OXPHOS), which drives myriad cellular processes. In addition to their role in maintaining bioenergetic homeostasis, changes in mitochondrial metabolism, permeability, and morphology are critical in cell fate decisions and determination. Notably, mitochondrial respiration coupled with the passage of electrons through the electron transport chain (ETC) set up a potential source of reactive oxygen species (ROS). While low to moderate increase in intracellular ROS serves as secondary messenger, an overwhelming increase as a result of either increased production and/or deficient antioxidant defenses is detrimental to biomolecules, cells, and tissues. Since ROS and mitochondria both regulate cell fate, attention has been drawn to their involvement in the various processes of carcinogenesis. To that end, the link between a prooxidant milieu and cell survival and proliferation as well as a switch to mitochondrial OXPHOS associated with recalcitrant cancers provide testimony for the remarkable metabolic plasticity as an important hallmark of cancers. In this review, the regulation of cell redox status by mitochondrial metabolism and its implications for cancer cell fate will be discussed followed by the significance of mitochondria-targeted therapies for cancer.
\end{abstract}

\section{Introduction}

The mitochondrion is a double-membraned organelle that was hypothesized to have evolved from a prokaryote to endosymbionts within eukaryotes [1]. The inner membrane folds on itself to form cristae, enclosing the granular matrix [2]. The significance of the resultant intermembrane space (IMS) is highlighted in its role in the production of cellular energy (ATP) through glycolysis, the tricarboxylic acid (TCA) cycle, and oxidative phosphorylation (OXPHOS). Cancer is characterized by the accumulation of multiple genetic alterations that give rise to multiple mutations, resulting in uncontrolled cell proliferation that requires high energy production and macromolecule synthesis. As such, cancer cells rely on processes such as glycolysis and TCA metabolism for cell survival.

The TCA cycle comprises of a series of biochemical reactions that contribute to energy production and macromolecule synthesis in the mitochondrial matrix. Under normal physiological conditions, the TCA cycle can be divided into two stages. First, citrate is converted into succinyl-CoA through a series of reactions that leads to decarboxylation, releasing two $\mathrm{CO}_{2}$ molecules and conversion of $\mathrm{NAD}^{+}$to $\mathrm{NADH}+\mathrm{H}^{+}$in the process. Second, succinate is converted to oxaloacetate through successive oxidation steps [3]. Intriguingly, tumor cells have been reported to harbor 
genetic alterations in enzymes involved in the TCA cycle such as succinate dehydrogenase $(\mathrm{SDH})$ and fumarate hydratase $(\mathrm{FH})[4,5]$. Loss of SDH and FH leads to the accumulation of ROS which, in turn, leads to DNA damage and altered cellular processes that contribute to oncogenesis.

Otto Warburg postulated that cancer cells rely on aerobic glycolysis, a term now known as Warburg effect. As such, the role of mitochondrial metabolism in tumorigenesis has been often overlooked until recent years where several evidences point to a reliance on mitochondrial respiration in some cancers. Hence, in this review, we discuss the regulation of mitochondrial metabolism and redox balance in tumorigenesis and evaluate therapeutic strategies designed to target these pathways in cancer.

\section{Mitochondrial Metabolism Regulates Cellular Redox Status}

2.1. Mitochondria as a Major Cellular Source of ROS. ROS are molecules that contain oxygen that is derived from incomplete reduction of $\mathrm{O}_{2}$. Some $\mathrm{ROS}$ molecules include superoxide $\left(\mathrm{O}_{2}{ }^{\bullet-}\right)$, hydrogen peroxide $\left(\mathrm{H}_{2} \mathrm{O}_{2}\right)$, and hydroxyl radical $\left(\mathrm{OH}^{\bullet}\right)$ [6]. ROS production could be attributed to nonmitochondrial ROS-producing enzymes such as NADPH oxidase (NOX) and xanthine oxide (XO) or as a result of electron leakage at the mitochondrial ETC. XO catalyzes the oxidation of xanthine and hypoxanthine in purine metabolism, which leads to the formation of $\mathrm{O}_{2}{ }^{\bullet-}$ and $\mathrm{H}_{2} \mathrm{O}_{2}$. NOX has also been reported to promote XO-dependent $\mathrm{O}_{2}{ }^{\circ-}$ production [7]. NOX family members are transmembrane proteins that generate ROS through the transport of electrons across biological membranes, leading to reduction of oxygen to $\mathrm{O}_{2}{ }^{\bullet}$. There are seven isoforms of NOX (NOX15 , DUOX1-2) that have been identified, each localized in different cell types. For example, NOX1 is commonly found in endothelial cells, neurons, and microglia; NOX2 is found in phagocytes and microvascular endothelial cells while NOX3 is found in renal cells $[8,9]$. Interestingly, the interaction between mitochondria and NOX, termed "ROS-induced ROS release" has been highlighted in glucose withdrawalinduced phospho-tyrosine signaling in glioblastoma (GBM) cell lines [10] and is suggested as a mechanism of ROS accumulation to sustain redox activation [11].

The aerobic nature of cellular respiration in the mitochondria makes ROS an inevitable by-product of the redox reactions. The dogmatic view is that excessive production of ROS could be detrimental to subcellular biomolecules, impair cellular processes, and trigger cell damage and death. Electron leakage in the mitochondrial ETC contributes largely to mitochondrial ROS accumulation. Complex I is the largest complex of the ETC and has been observed to be a major source of ROS under pathological conditions. This is due to mutations in the complex I subunits found in approximately $40 \%$ of mitochondrial disorders including diabetes and cancer $[12,13]$. The Q-cycle is the mechanism of $\mathrm{O}_{2}{ }^{\bullet-}$ production in complex III, another complex in the ETC. Complex III transfers the electrons from complexes I and II to cytochrome c, and in the process, protons translocate into the inner mitochondrial membrane (IMM). As a result, electrons leak and interact with $\mathrm{O}_{2}$, producing $\mathrm{O}_{2}{ }^{--}$in the IMM and mitochondrial matrix [14]. In the cancer context, overexpression of complex III subunits such as UQCR2 and UQCRH has been observed to induce tumorigenesis in colorectal cancer [15], lung carcinoma, and hepatocarcinoma [16] in a ROS-dependent manner. This highlights the role of mitochondrial metabolism in maintaining the redox balance and tumorigenesis.

2.2. Cellular Antioxidant Defense Systems. In most cellular processes, homeostatic balance is important in maintaining normal functioning of cells. The production of ROS is countered by antioxidant systems [17], which scavenge harmful ROS that can cause oxidative damage resulting in DNA point mutations [18, 19], disrupted lipid membranes [20], and altered protein function [21-23]. Amongst the many enzymatic antioxidant defenses are the various superoxide dismutase (SOD) and the glutathione (GSH) system. SOD is a family of enzymes that catalyzes the conversion of $\mathrm{O}_{2}{ }^{\bullet-}$ to $\mathrm{H}_{2} \mathrm{O}_{2}$. In mammals, there are three SODs: cytoplasmic SOD1 (Cu/ZnSOD), extracellular SOD3 (ecSOD) [24, 25], and mitochondrial manganese-dependent SOD2 (MnSOD) [26]. MnSOD is shown to be downregulated in several cancers including lung carcinomas [27, 28]. Intriguingly, MnSOD was observed to be increased in tumor tissues and is associated with drug resistance [29, 30]. Furthermore, MnSOD expression is reportedly increased in aggressive breast cancer and influences epithelial-mesenchymal transition (EMT) in breast cancer [31, 32]. The glutathione peroxidase family (GPx) utilizes reduced GSH as the cofactor in reducing $\mathrm{H}_{2} \mathrm{O}_{2}$ into harmless $\mathrm{H}_{2} \mathrm{O}$. During the reduction of $\mathrm{H}_{2} \mathrm{O}_{2}$, cofactor $\mathrm{GSH}$ is oxidized and disulphide bonded into a GS-SG dimer. Glutathione reductase is then responsible for reducing the GS-SG dimer, replenishing the GSH cofactor for further antioxidant activity [33]. Modified GPx expression has been observed in several cancers such as breast cancer [34], gastric cancer [35, 36], and thyroid cancer [37].

\section{Dichotomy of Redox Signaling in Cancer Cell Fate Decisions}

Depending on the type and concentration, ROS can impact cell fate signaling. As a matter of fact, cellular redox status serves as a double-edged sword from the standpoint of carcinogenesis and its progression, as summarized in Figure 1. At moderate but sublethal concentrations, a mild oxidative stress milieu can have prosurvival/proliferation properties. Coupled with the ability of cells to mount sufficiently effective antioxidant defenses, an association between a "prooxidant" environment and processes that favor tumor progression such as metastasis has been strongly suggested $[38,39]$.

3.1. Conventional Dogma: ROS are Onco-Suppressors. Conventionally, increased ROS levels have also been implicated in tumor cell growth inhibition. Interestingly, the reactive intermediates damage biomolecules such as membrane lipid bilayer, leading to lipid peroxidation; $\mathrm{OH}^{\bullet}$ radical has been 


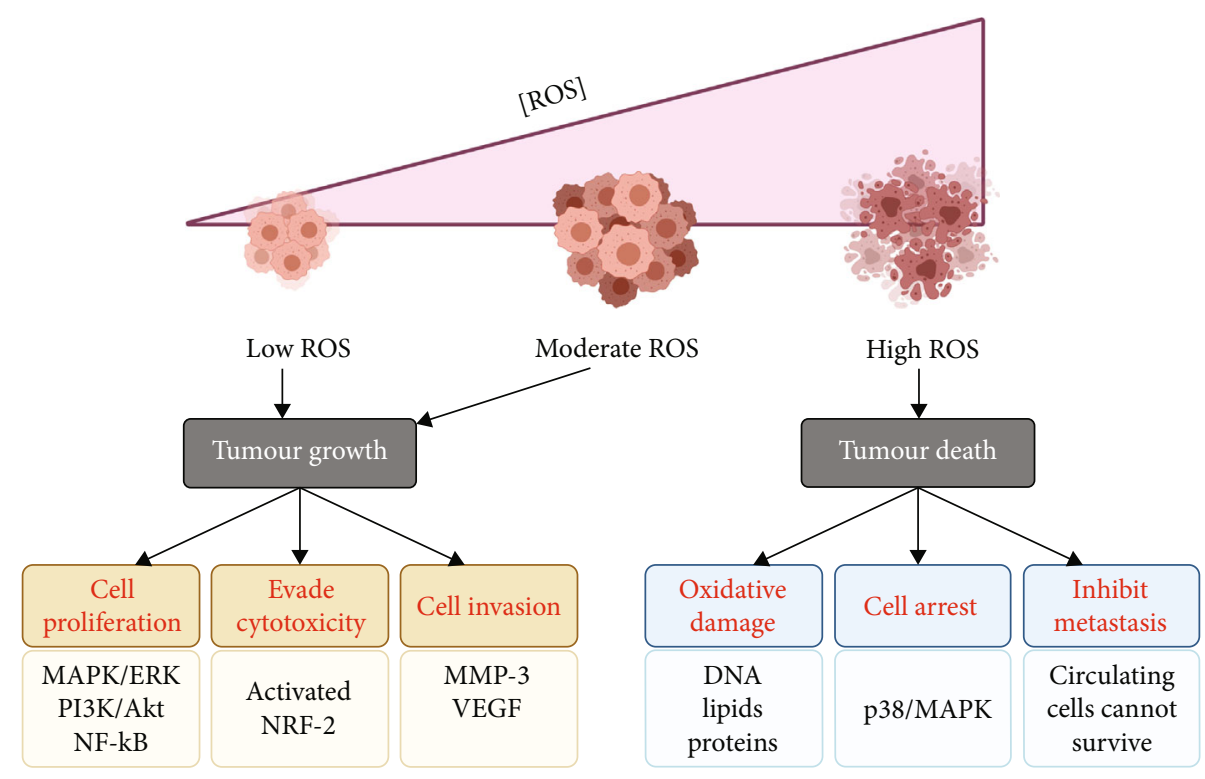

FIgURE 1: Regulation of carcinogenesis by ROS. At different ROS levels, cells experience a dichotomous fate. Moderate and low ROS levels tend to promote cell growth and uncontrolled proliferation, thus, promoting carcinogenesis and/or its progression. On the other end of the spectrum, high ROS levels tip the balance to cell death, preventing further growth of the tumor. Figure created with biorender.com.

shown to attack unsaturated lipids, generating lipid hydroperoxides [40]. A notable by-product of lipid peroxidation is 4-hydroxynonenal (4-HNE) that is found to exert cytotoxic and genotoxic effects [41]. Moreover, low levels of 4HNE reportedly inhibit c-Myc expression and cell proliferation in leukemia cell lines [42, 43], suggesting an association between ROS-induced lipid peroxidation and inhibition of cancer progression. Furthermore, 4-HNE has been shown to activate both the intrinsic and extrinsic apoptotic pathways [44] as high peroxidation rates overwhelm natural antioxidant systems causing the cells to undergo programmed cell death, thus, highlighting the role of ROS in inhibiting tumor cell growth.

Metastasis can similarly be limited upon exposure to an oxidizing stimulus. Increased oxidative stress inhibits proliferation and survival of circulating cancer cells [45]. In an in vivo study conducted by Piskounova et al., NSG mice were subcutaneously transplanted with metastasizing melanoma cells and treated with antioxidant N-acetyl-cysteine (NAC). Interestingly, NAC treated mice were observed to have greater frequency of circulating melanoma cells and increased metastatic disease burden, thereby suggesting that oxidative stress limits the metastatic capacity of melanoma cells [45].

Low dose of ROS activates p53, a tumor suppressor that regulates cellular apoptosis, DNA repair, and cell cycle arrest. Upon ROS activation, p53 in turn downregulates prosurvival proteins such as $\mathrm{Bcl}-2$ and $\mathrm{Bcl}-\mathrm{xL}$ while activating proapoptotic genes such as Bax, PUMA, and NOXA transcriptionally [46]. Datta et al. showed that in the presence of $\mathrm{H}_{2} \mathrm{O}_{2}$, p53 expression and cell apoptosis were induced. Furthermore, $\mathrm{H}_{2} \mathrm{O}_{2}$-induced apoptosis was abrogated in the presence of p53 antisense oligonucleotides. Similarly, p53-null U373MG cells are resistant to $\mathrm{H}_{2} \mathrm{O}_{2}$-induced apoptosis [47]. The role of p53 in mediating $\mathrm{H}_{2} \mathrm{O}_{2}$-induced apoptosis is supported by Kitamura et al. where they demonstrated an increase in p53 expression as well as Bak, p21WAF1/CIP1 proteins upon $\mathrm{H}_{2} \mathrm{O}_{2}$ treatment [48]. Interestingly, mutant p53 in turn induces ROS accumulation and enhances ROS level through regulation of ROS-related transcription factors such as PGC1- $\alpha[49,50]$. ROS levels were also seen elevated in p53-induced senescent and apoptotic cells along with decrease in GSH levels in prostate cancer cells [50].

Intriguingly, ROS has been implicated in senescenceinduced tumor suppression in several cellular senescence studies. It is noteworthy that ROS-induced oxidative damage is a signal for irreversible cell cycle arrest or senescence [51]. In particular, telomeres are observed to be sensitive to increase in ROS [52], supporting the view that mtROS results in telomere dysfunction and therefore premature senescence [53]. ROS can also serve as secondary messengers in senescence-inducing pathways such as p53/p $21^{\mathrm{WAF} 1}$ [54], p $16^{\mathrm{INK}-4 \mathrm{a}}[55]$, and $\mathrm{p} 38^{\mathrm{MAPK}}[56,57]$. Senescence is closely associated with $\mathrm{p} 16^{\mathrm{INK}-4 \mathrm{a}}$, and Takahashi et al. demonstrated that ROS determines irreversibility of senescence-induced cell cycle arrest and treatment with NACrescued cells and reinitiates cell proliferation, suggesting a role of ROS in regulating tumor suppression through senescence [58].

3.2. Flip Side of the Coin: ROS are Oncogenic. Interestingly, while ROS has been shown to affect cell fate and signaling in cancer, in a rapidly proliferating cell, such as a cancer cell, increased metabolic activity in turn leads to high levels of ROS.

3.2.1. ROS Regulation of Keap1/Nrf2 Complex. As a protective measure, reinforcement of antioxidant defenses such as the Nrf2 pathway provides cells with the ability to adapt, thereby evading oxidative stress-mediated cytotoxicity and 
tissue damage. Nrf2 is a transcription factor that controls nuclear antioxidant response elements (ARE) in the promoter region of target genes [59], such as those utilized by oncogenes K-Ras $^{\mathrm{G} 12 \mathrm{D}}$ and $\mathrm{B}-\mathrm{Raf}^{\mathrm{V} 619 \mathrm{E}}$ in human pancreatic cancer cells in vivo [60] and in vitro [61]. Further supporting that, Nrf2-knockout mice exhibit increased oxidative stress and predilection for carcinogenesis [62, 63]. Aside from the direct effect of $\mathrm{Nrf} 2$ on antioxidant defense reinforcement, increased oxidative stress also promotes stability of Nrf2 via oxidative modification of its regulator Keap1, which promotes Nrf2 proteasomal degradation by polyubiquitination [64]. Keap1 has redox-sensitive cysteine thiols that are prone to modification by $\mathrm{H}_{2} \mathrm{O}_{2}$, altering the Keap1/Nrf2 complex and ultimately inhibiting Nrf2 degradation [65]. Other antioxidant systems like glutathione and thioredoxin have also been shown to promote breast tumor progression in a synergistic manner [66]. However, in other cancer types such as lung [67] and prostate [68], SOD2 levels have been found suppressed, hence, suggesting that the regulation of intracellular antioxidants depends on the primary tumor.

\subsubsection{Oncogenic Mutations Tilt the Balance of ROS. ROS} levels could also be affected by oncogene mutations arising from chromosomal translocations. The fusion protein $\mathrm{BCR} / \mathrm{ABL}$ in the Philadelphia chromosome is characteristic of predominantly chronic myeloid leukemia (CML) and acute lymphoblastic leukemia (ALL) [69]. This hybrid protein has constitutive tyrosine kinase signaling properties that allow uncontrolled cell cycle progression [70]. Increased $\mathrm{H}_{2} \mathrm{O}_{2}$ levels have been found in BCR/ABL-activated cell lines [71-73], followed by a decrease of $\mathrm{BCR} / \mathrm{ABL}$ activity in the presence of antioxidants [73]. Additionally, ROS from BCR/ABL activation can further mutate the fusion $\mathrm{BCR} / \mathrm{ABL}$ gene to confer therapeutic resistance against specific tyrosine kinase inhibitors [74]. Another chromosomal translocation is NPM/ALK, which also displays upregulated tyrosine kinase activity in anaplastic large-cell lymphoma (ALCL) [75]. The mutation leads to downstream ROS production via the lipoxygenase enzyme family [76], where ROS can act as secondary messengers to activate pathways implicated in tumorigenesis such as MAPK for metastasis [77].

3.2.3. ROS-Mediated Genome Instability. As genomic instability is a hallmark of cancer [78], ROS-mediated DNA damage hints to cancer formation. Under oxidative stress, ROS oxidizes DNA bases. The most common oxidation is guanine to 8-oxo-dG due to it having the lowest reduction potential amongst the other bases [79-82]. 8-oxo-dG is a DNA lesion and can lead to permanent mutations which modify gene expression. In 1990, the association between 8-oxo-dG and carcinogenesis was established [83] although the direct link has not been found. Notably, DNA changes such as base substitutions occur in cells with artificially added 8-oxo-dG [84]. A common mutation is the transversion of oxidized guanine to thymine $[85,86]$. As a matter of fact, 8-oxo-dG has been proposed as a marker of neoplastic transformation, thus, linking oxidation-induced DNA damage to carcinogenesis [87].
Genomic instability is promoted by the loss of tumor suppressors that control cell cycle progression and DNA damage repair process, such as the master transcription factor, $\mathrm{p} 53$, which is mutated in more than $50 \%$ of human solid tumors $[88,89]$. At moderate sublethal ROS, p53 upregulates antioxidants to evade oxidative stress [90-92]; however, in the face of cytotoxic ROS levels, p53 downregulates antioxidants to tip the cell towards apoptosis $[93,94]$. As such, the dual role of p53 in regulating cellular redox state switches the pendulum from survival to death execution [95]. Mechanistically, loss-of-functional of p53 increases ROS levels via the TP53-inducible glycolysis and apoptosis regulator (TIGAR). TIGAR normally shifts carbon from glycolysis to the pentose phosphate pathway (PPP) by degrading the allosteric activator of phosphofructosekinase-1 (PFK1) and NADPH generated from PPP can fuel antioxidant processes by glutathione $[92,96]$. Reduced GSH can then convert $\mathrm{H}_{2} \mathrm{O}_{2}$ to water, reducing ROS levels. Without functional p53, ROS levels are no longer regulated by the TIGAR-dependent process. Besides the downstream ROS effects of p53, it is worthy to mention that p53 itself contains conserved cysteine residues that are susceptible to redox modification [97].

3.2.4. Effect of ROS on Signaling Pathways. ROS can also damage functional proteins directly by oxidizing susceptible catalytic thiol groups in enzymes [19, 22, 98]. In this regard, ROS can activate signaling pathways that promote cell proliferation and survival as a secondary messenger [99]. A large body of evidence appears to implicate intracellular $\mathrm{H}_{2} \mathrm{O}_{2}$, due to its diffusion efficiency and ubiquitous nature in most cells, as the major ROS involved in most physiological redox signaling [100]. The mechanism of ROS signaling is via its oxidation of thiol "switches" [101] in redoxsensitive substrates that have conserved cysteine residues $[102,103]$. To that end, increased ROS has been shown to activate PI3K/Akt pathway to drive cell survival via inactivation of its regulator protein, phosphatase and tensin homo$\log (\mathrm{PTEN})[22,104]$; exogenously added $\mathrm{H}_{2} \mathrm{O}_{2}$ can directly oxidize cysteine residues on PTEN, thereby compromising its PI3K/Akt-regulating activity [19, 22, 105] (Figure 2). Interestingly, constitutively activated PI3K/Akt pathway results also results in an increase in intracellular $\mathrm{O}_{2}{ }^{\bullet-}$ production as a side-product from the generation of prostaglandin by COX enzymes with peroxidase activity [106, 107]. The involvement of NOX family of oxidase has also been shown in Akt-induced $\mathrm{O}_{2}{ }^{--}$production [108], which has been associated with mutation(s) of RAS, an oncogene that is constitutively activated in approximately $20-30 \%$ of human cancers [109]. RAS is a GTPase protein that is activated downstream of growth factor receptor tyrosine kinase (e.g., EGFR) which then activates PI3K by phosphorylation. Although NOX-mediated ROS production is mainly recognized for phagocytic respiratory burst, and its significance in tumor angiogenesis and metastasis is not dismissed [110]. Direct pathway components can also increase ROS levels, such as the catalytic subunit of PI3K (encoded by PIK3CA), which are found to be mutated in most solid tumors [111-113]. Mutated PIK3CA cell lines were 


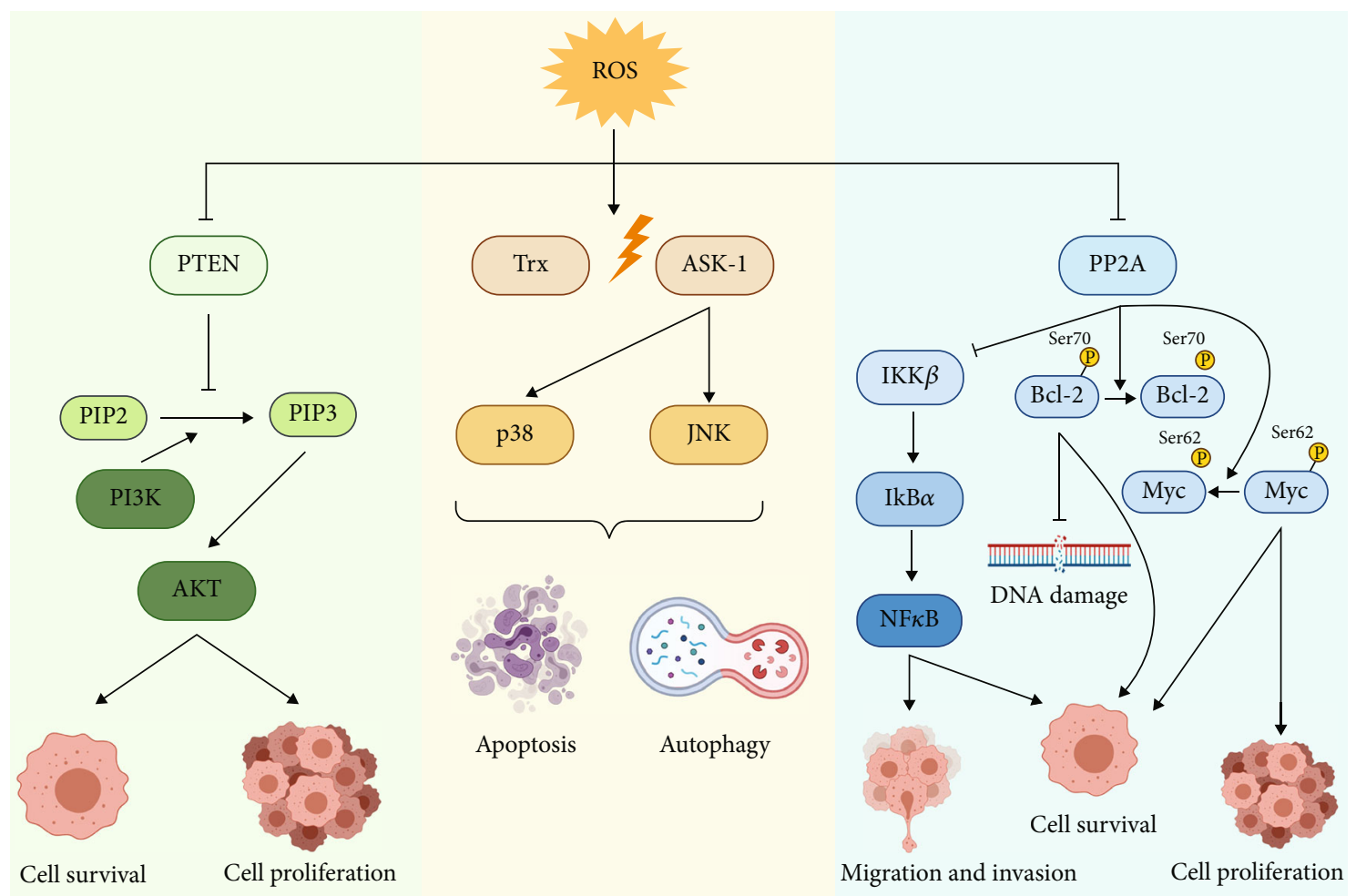

FIGURE 2: ROS regulation of signaling pathways in cancer. ROS has been demonstrated to regulate signaling pathways in cancer. Increase in ROS such as $\mathrm{H}_{2} \mathrm{O}_{2}$ activates PI3K/Akt signaling pathway through the inhibition of PTEN, resulting in constitutive activation of PI3K/Akt that contributes to cell survival and proliferation in cancer. Similarly, ASK-1, a kinase in the MAPK signaling cascade, is displaced from Trx-ASK1 complex under oxidative stress. ASK-1 subsequently activates downstream p38 and JNK, leading to apoptosis and autophagy. Redox-mediated inactivation of PP2A was reported to sustain NF- $\kappa$ B activation, Bcl-2 phosphorylation at Ser70, and Myc phosphorylation at Ser62, leading to cell migration and invasion, inhibition of DNA damage and cell proliferation, respectively. Figure created with biorender.com.

observed to display raised $\alpha$-KGDH activity, a source of ROS [114]. Further corroborating this, negative regulators of the PI3K pathway, such as PTEN, are tumor suppressors that can be modulated by ROS.

Similarly, signaling pathways like the mitogen-activated protein kinase (MAPK/ERK) have demonstrated mediation by ROS, and other studies conversely demonstrate the ability of antioxidants to alleviate MAPK activation [77]. Oxidative stress upon exposure to exogenously added $\mathrm{H}_{2} \mathrm{O}_{2}$ also correlated with MAPK activation [115, 116]. For example, apoptosis signal-regulating kinase-1 (ASK-1), a kinase in the MAPK signaling cascade, is displaced from antioxidant protein, thioredoxin, under oxidative stress, and oligomerizes to activate downstream p38 and c-jun N-terminal kinase (JNK) [117]. Moreover, ASK-1 expression has been associated with gastric cancer progression, where cell proliferation decreased in ASK-1 knockdown gastric cancer cells [118]. Since oxidative stress is reportedly the most common activator of ASK-1, this highlights the prominent role of oxidative stress in carcinogenesis through the regulation of signaling pathways (Figure 2).

3.2.5. Oxidative Stress-induced Metastasis, Angiogenesis and Cell Death Inhibition. Oxidative stress is also able to drive hallmarks involving cell motility and invasion such as metastasis and angiogenesis. Kundu et al. demonstrated that exposure to sublethal exogenous $\mathrm{H}_{2} \mathrm{O}_{2}$ in murine cancer cells increased rates of metastasis and anchorageindependent survival while reducing tumor cell adhesion to ECM [119]. $\mathrm{H}_{2} \mathrm{O}_{2}$ has been shown to regulate the expression of matrix metalloproteases (MMPs) that disrupt the ECM to facilitate cancer cell invasion [120]. Along similar lines, MMP-3 was shown to increase oxidative stress and induce EMT in murine mammary epithelial cells [121]. Moreover, $\mathrm{H}_{2} \mathrm{O}_{2}$-associated EGFR signaling is also vital for tumor metastasis [122], where murine metastatic melanoma colonies had greater EGFR expression [123]. Oxidative stress has been shown to stabilize HIF- $1 \alpha$ and allow the initiation of VEGF expression, which leads to the induction of angiogenesis [124], thus, supplying oxygen and nutrients to hypoxic tumors [125]. Furthermore, the NF- $\kappa$ B pathway associated with processes involved in carcinogenesis such as inflammation, cell survival, migration, and invasion is activated by $\mathrm{H}_{2} \mathrm{O}_{2}$ via IKK-dependent mechanism [126] as well as by redox-mediated inactivation of the phosphatase PP2A [127], which regulates phosphorylation-dependent degradation of $\mathrm{I} \kappa \mathrm{B} \alpha$, further corroborating the involvement of ROS in processes associated with metastasis. Likewise, redox-mediated inactivation of PP2A has also been associated with phospho-stability of the antiapoptotic protein 
Bcl-2 (pS70) and oncogene c-Myc (pS62), specifically implicating $\mathrm{O}_{2}{ }^{--}$-mediated $\mathrm{ONOO}^{-}$induced tyrosine nitration $[128,129]$. Sustained pS70 of Bcl-2 in turn blocks oxidative stress-induced DNA damage to promote cancer cell survival [130]. Similarly, death receptor inhibitory protein, cFLIP, was shown to be upregulated upon an increase in intracellular $\mathrm{O}_{2}{ }^{--}$, thereby blunting death receptor signaling [131].

\section{Redox Dysregulation and Mitochondrial Metabolism in Cancer}

4.1. Warburg and Reverse Warburg Effects. Mitochondrial ROS can impact mitochondrial function, which can ignite further imbalance in redox homeostasis. The main mitochondrial function is the metabolism of organic substrates such as glucose, lipids, amino acids, and nucleic acids. In terms of energy production from cellular respiration, the metabolism of glucose for ATP has been observed to be dysregulated in cancer cells that are actively proliferating. As mentioned earlier, the Warburg effect postulated that cancer cells rely on aerobic glycolysis to rapidly produce energy for proliferation due to mitochondria dysfunction and suppression of OXPHOS. Pyruvate is an end-product of glycolysis that exerts antioxidant effect and protects the mitochondria from oxidative damage [132]. Wang et al. reported that pyruvate is able to inhibit $\mathrm{O}_{2}{ }^{-}$production in the presence of mitochondrial complex inhibitors and inhibits mitochondrial ROS generation to a greater extent compared to intracellular ROS levels [132]. Moreover, it was observed that intracellular increase in ROS levels leads to inhibition of pyruvate kinase M2 isoform (PKM2), a glycolytic enzyme that plays a vital role in catalyzing the conversion of phosphoenolpyruvate to pyruvate [133]. PKM2 has also been reported to serve as a metabolic sensor under glucosestarved conditions, as inhibition of PKM2 was observed to enhance metabolic activity and protect against apoptotic cell death [134].

However, this milestone discovery is challenged by studies demonstrating that glycolysis accounted for less than half of the ATP produced in multiple malignant cell lines [135]; OXPHOS still contributed the majority of ATP during normoxia and lesser than $50 \%$ during hypoxia in malignant breast and cervical cell lines [136, 137]. The effectively coined "Reverse Warburg Effect" has brought attention to the tumor microenvironment (TME), where stromal cells such as cancer-associated fibroblasts (CAFs) could be responsible for allowing malignant cells to produce ATP while reducing reliance on OXPHOS [138, 139]. Oxygen becomes a limiting factor when proliferation is uncontrolled, producing ROS such as $\mathrm{H}_{2} \mathrm{O}_{2}$ to initiate CAF production of high energy metabolites such as pyruvate and lactate. These products are then transported to the tumor cells to be funneled into OXPHOS to produce a significant amount of ATP [140], demonstrating altered metabolism within tumor mitochondria. In fact, OXPHOS has been shown to be upregulated in ovarian cancer stem cells [141] as well as drug-resistant cancers [142-144] which give rise to an emerging number of studies on targeting OXPHOS in cancer therapy.
4.2. ROS and Nuclear-Encoded Mitochondrial Proteins. Nuclear-encoded mitochondria genes are susceptible to oxidative damage (Figure 3). Some of the protein products of nuclear-encoded mitochondrial genes include $S D H[4,5]$ and $\mathrm{FH}$ [5]. Inactivation of these enzymes by $\mathrm{H}_{2} \mathrm{O}_{2}$ [145] or by somatic mutations in the enzymatic subunits [5] could reduce the rate of ATP and ROS production during OXPHOS. The inactivation of these enzymes could trigger cellular transformation, as evidenced by the association of $S D H$ subunit mutations with paraganglioma [146, 147]. $\mathrm{SDH}$, also known as complex II of the mitochondrial ETC, is an important ROS-producing site, which either generates ROS directly from the release of electrons from the conversion of FAD to $\mathrm{FADH}_{2}$ under low succinate concentration condition, or indirectly through reverse electron transfer (RET) in the presence of high concentration of succinate, forcing electrons through complex I [148]. Loss of function mutations in $S D H$ reported in HPGL/PCC cancer could lead to an accumulation of succinate and ROS which leads to further oxidative stress and DNA hypermutations [149].

Similarly, altered FH activity has been implicated in renal cell carcinoma and uterine leiomyoma [150-152]. Patients with germline mutations in $\mathrm{FH}$ were also observed to have a higher risk in cancers such as renal cell cancer, breast, and bladder cancer [134]. As FH catalyzes the conversion of fumarate to malate, loss-of-function mutations of $F H$ lead to fumarate build up, which can activate Nrf2 by inhibiting Keap1 [153]. The protective effect of the genes regulated by Nrf2 downstream of the ARE, such as heme oxygenase 1 (HMOX1), promote tumorigenesis by alleviating oxidative stress $[154,155]$.

In addition, nuclear-encoded Suppressor of Var1 (SUV3) RNA helicase is responsible for mitochondria DNA (mtDNA) replication and murine haploinsufficiency of SUV3 allele predisposes to tumorigenesis in vivo [156], indicating its role as a tumor suppressor. Furthermore, complete knockdown of SUV3 results in a decrease in mtDNA copy number and, subsequently, together with an increase in $\mathrm{O}_{2}{ }^{--}$formation and enhanced tumorigenesis [157]. SUV3 knockdown also observed change in mitochondrial morphology and eventual senescence [156].

4.3. ROS and Mitochondria-Encoded Proteins. Since mitochondria are an important source of ROS, mtDNA is highly vulnerable to oxidative stress-induced damage in the prooxidant milieu of cancer cells, as mtDNA is not protected by histone proteins [158]. The mitochondrial genome encodes for 13 OXPHOS subunits, 22 tRNAs, and 2 rRNAs [159], including cytochrome proteins that are critical for optimal functioning of the ETC (Figure 3).

4.3.1. Cytochrome c Oxidase (COX). In particular, mitochondria-encoded COX displays antioxidant activity to lower ROS levels, which prevents further oxidative damage [160]. Furthermore, studies have also reported a decrease in COX activity and expression, associated with increased ROS production in human colon adenocarcinoma $[161,162]$ and murine hepatoma cells [163]. 


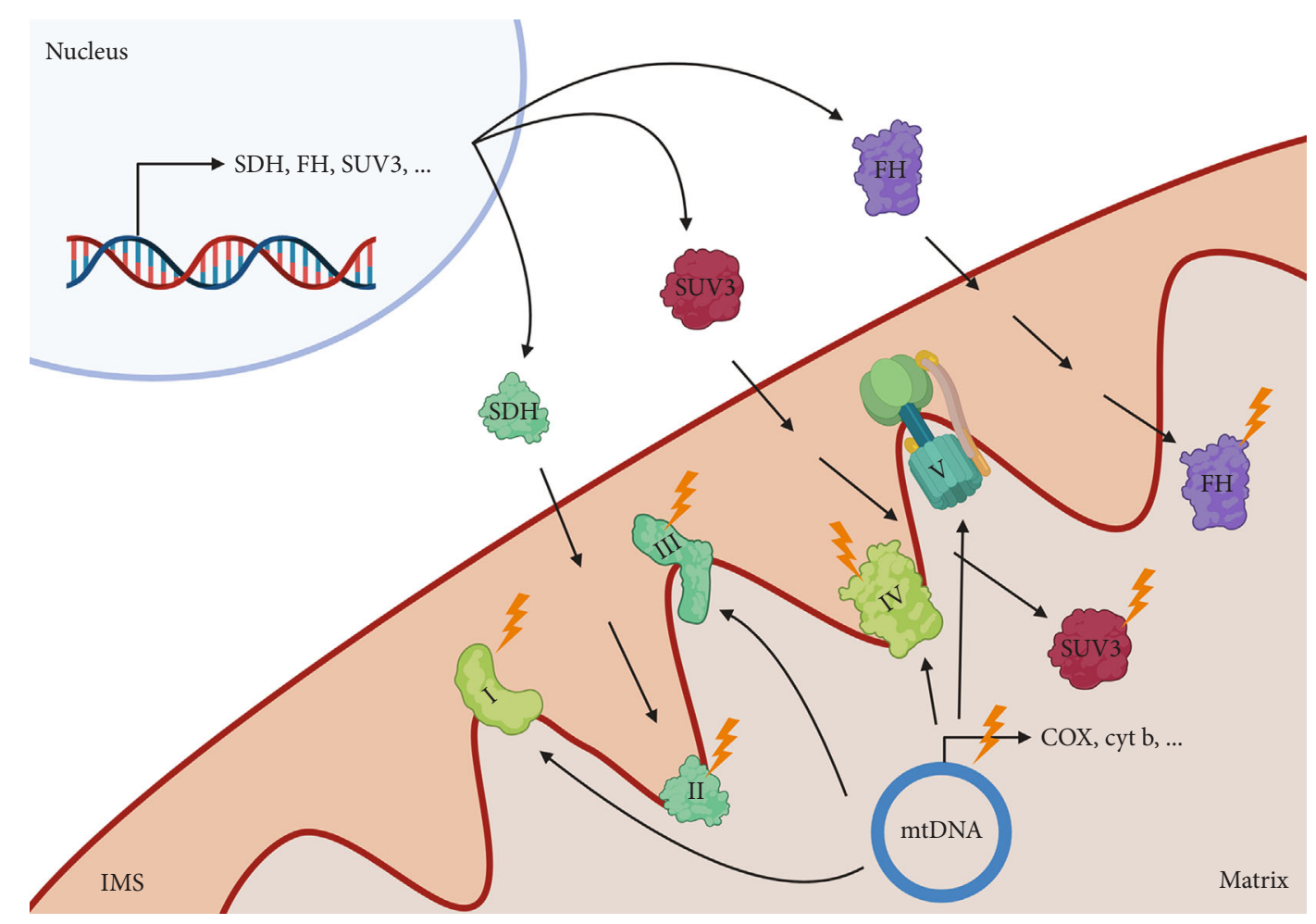

FIGURE 3: Nuclear-encoded and mitochondrial-encoded mitochondria regulatory genes are susceptible to oxidative damage. Nuclearencoded mitochondrial genes such as SDH, which makes up complex II of the ETC, are assembled and transported into the mitochondria and susceptible to inactivation by ROS such as $\mathrm{H}_{2} \mathrm{O}_{2}$. In addition, $\mathrm{FH}$ generates energy for the cells by converting fumarate into malate in the TCA cycle, and SUV3 is a nuclear-encoded ATP-dependent DNA/RNA helicase and function as a tumor suppressor. The mtDNA encodes for subunits of the ETC and regulatory proteins that are important for the assembly and function of the ETC. The mtDNA is highly susceptible to oxidative stress-induced damage, leading to OXPHOS dysregulation. Figure created with biorender.com.

4.3.2. Cytochrome b. MtDNA also codes for cytochrome $b$, which is the only component of complex III encoded by the mtDNA. Cytochrome b is found to be mutated in bladder cancer, which leads to increased ROS production coupled with amplified NF- $\kappa \mathrm{B}$ signaling and tumor cell growth. Overexpression of $m t C Y B$ was associated with increased tumor growth and invasion in vivo. Interestingly, inhibition of ROS inhibited cell proliferation driven by NF$\kappa \mathrm{B}$, thus, suggesting that increase in ROS upon cytochrome $b$ mutation is involved in mediating cell proliferation in bladder cancer [164].

4.3.3. Mitochondrial-Encoded Complex I. The mtDNA codes for 7 subunits of the complex I-ND1, ND2, ND3, ND4, ND4L, ND5, and ND6. Mutations in mtDNA most commonly affect complex I genes and induce feedback induction of Warburg effect and AMPK activation. Iommarini et al. also demonstrated that different degrees of complex I dysfunction induced differential oxidative stress. Severe mutations lead to complex I disassembly, inhibiting the transfer of electrons to ROS-generating complexes leading to inhibition of ROS generation [165].

4.3.4. ATP Synthase. mtDNA codes for 2 subunits of ATP synthase-MT-ATP6 and MT-ATP8. Mutations occur at two amino acid positions $8993 \mathrm{~T}>\mathrm{G}$ and $8993 \mathrm{~T}>\mathrm{C}$, which has reportedly caused $90 \%$ and $70 \%$ deficit, respectively, in ATP synthase function due to inefficient assembly and stability of the subunit [166]. Mutations in ATP6 and ATP8 genes were observed in breast cancer although functional effect of the mutation has yet to be studied widely in the model [167].

4.4. Effect of Aberrant ROS Signaling on Mitochondrial Apoptotic Pathway. Altered redox metabolism also regulates mitochondrial (intrinsic) apoptotic signaling. Singh et al. demonstrated that $\mathrm{H}_{2} \mathrm{O}_{2}$ induces $\mathrm{Bax}$ expression with a reciprocal decrease in antiapoptotic protein $\mathrm{Bcl}-\mathrm{xL}$ in $\mathrm{HeLa}$ cells, which triggered cytochrome $\mathrm{c}$ release from mitochondria [168]. This is supported by several studies demonstrating the importance of $\mathrm{H}_{2} \mathrm{O}_{2}$ as a signaling molecule for apoptosis induction [169-171]. On the other hand, $\mathrm{H}_{2} \mathrm{O}_{2}$ was observed to inhibit drug-induced apoptosis through the depletion of cellular energy (ATP) by activation of PARP $[172,173]$, hence, suggesting a dual role of $\mathrm{H}_{2} \mathrm{O}_{2}$ in regulating apoptotic signaling. Other redox-sensitive proteins such as VDAC and ANT can stimulate MOMP and cytochrome $\mathrm{c}$ release upon exposure to $\mathrm{H}_{2} \mathrm{O}_{2}$ or $\mathrm{O}_{2}{ }^{\bullet-}[169,174,175]$. Furthermore, increased $\mathrm{H}_{2} \mathrm{O}_{2}$ levels coincide with increased FADD intermembrane translocation and FasL, which activate initiator caspase- 8 in the extrinsic apoptotic pathway, 
whereas decreasing $\mathrm{O}_{2}{ }^{--}$sensitizes $\mathrm{Bcl}-2$ overexpressing cancer cells to receptor or drug-induced apoptosis $[176,177]$. Collectively, these findings highlight the critical role of an altered redox state in mitochondria-dependent apoptotic execution.

\section{Targeting Mitochondria as a Therapeutic Strategy}

Since cancer cells harness ROS at a level that stimulates proliferative and survival signaling without being cytotoxic, therapeutics aim to create oxidative stress to drive transformed cells towards apoptotic clearance. Here, we compare several compounds developed to target mitochondria and ROS production in cancer (Table 1, Figure 4). The oxidative burden generated can also confer sensitivity to other anticancer drugs.

5.1. Complex I Inhibitors. Although metformin was developed as a diabetic drug, there is an increasing interest in its anticancer properties through inhibition of complex I of the ETC, which disrupts ATP production by OXPHOS. Metformin was also reported to indirectly reduce mitogenic insulin growth factors when controlling blood glucose and preventing PI3K activation of cell proliferation [178]. Metformin exerts antioxidant properties through inhibition of protein kinase $\mathrm{C}$ activity and, in turn, leading to decreased ROS production [179]. The clinical efficacy was reflected in the phase III randomized trial breast cancer patients where the compound displayed increased progression-free survival (NCT01101438). In addition, the efficacy of metformin in combination with chemotherapy such as gemcitabine as well as targeted therapies such as erlotinib such as tyrosine kinase inhibitors (TKI) has been evaluated in phase II clinical trials in pancreatic cancer patients (NCT01210911), although more studies need to be conducted to evaluate the safety and efficacy of combination therapies with metformin.

Small molecule inhibitor IACS-010759 also attacks complex I, displaying in vitro benefits in both AML and CLL. AML cells were sensitive to IACS-010759 treatment where cell viability and oxygen consumption rate were decreased [180]. In CLL, tumor cells exposed to IACS-010759 had lower OXPHOS rates but adapted by relying on glycolysis for survival, highlighting that maximum IACS efficacy can be achieved by inhibiting both glycolysis and OXPHOS [181]. A recent phase I trial also pointed out the antitumor potential of IACS-010759 in pancreatic cancer, triplenegative breast cancer, and SWI/SNF-related tumors (NCT03291938) [182]. Combination therapy of complex I inhibitor IACs-010759 with vinorelbine was shown to have a synergistic effect in primary cells of AML patients [183]. Currently, IACS-010759 is also in phase I study in relapsed/refractory AML (NCT02882321) and variety of solid tumors (NCT03291938) as well as BCL2 inhibitor venetoclax (ABT-199). Dual therapy of IACS-010759 with venetoclax has shown elimination of leukemic cells in in vitro and in vivo AML models by inhibiting mitochondrial respiration and BCL2/VDAC interaction [184]. IACS-010759 has also shown prolonged survival effect in PD-1 resistant NSCLC in combination with radiation therapy and anti-PD1 by inhibiting RT-induced immunosuppression [185].

OPB-51602 (OPB) is another novel complex I inhibitor that has shown high specificity and produced antitumor effects in drug-resistant cancer cell lines [143]. A previous phase I trial on OPB's clinical effectiveness showcased preliminary benefits of OPB in TKI-resistant cancers [186]. Although known to restrict respiration by interfering with STAT3 signaling [187], Hirpara et al. have demonstrated that OPB specifically inhibits complex I due to increase in $\mathrm{O}_{2}{ }^{-}$production and reduction in $\mathrm{NAD}^{+} / \mathrm{NADH}$ ratio, an indicator of complex I inhibition. Furthermore, OPB proved effective in patients with TKI-resistant EGFR mutation NSCLC, by reducing tumor burden significantly [143]. OPB was also shown to have significant sensitizing effect with TKI in variety of cancer cells [186].

5.2. ATP Synthase Inhibitor. The final OXPHOS step can also be targeted by ATP synthase inhibitors such as oligomycin [188]. The disruption of ATP production similarly causes $\mathrm{O}_{2}{ }^{--}$formation from resultant electron leaks in the ETC. Oligomycin is found to specifically inhibit membrane-bound $\mathrm{F}_{\mathrm{O}}$ region of ATPase [189]. Recent studies demonstrate how oligomycin helps resensitize leukemic cells to TKI treatment [190]. The treated leukemic cells were subsequently responsive to $\mathrm{Bcr} / \mathrm{Abl}$ inhibition, where they had decreased ATP production and increased superoxide production and apoptosis occurrences [190].

A novel ATP synthase inhibitor that has similar effects to oligomycin is positively charged Gboxin, which interacts with the ETC complexes I, II, IV, and ATP synthase to restrict ATP synthase activity in glioblastoma (GBM) [191]. Gboxin-sensitive GBM cells lacked expression of mitochondrial permeability transition pore (mPTP) that could prevent ROS accumulation in the mitochondria, hence, making them susceptible to Gboxin. Gboxin significantly increased mitochondrial membrane potential, with contrast to complex I and III poisons (rotenone and antimycin respectively) which reduced the membrane potential [191]. Gboxin analogue (S-Gboxin) for in vivo studies also demonstrated inhibited GBM growth, indicating promising antitumor potential [191].

5.3. Mitochondria Biogenesis Targeting Compounds. On top of direct inhibition of the mitochondrial ETC complex activity, there is an emerging interest in targeting mitochondria biogenesis, which is a process defined by an increase in mitochondria mass through the increase in size and number of mitochondria in cells. Mitochondria alleviate oxidative stress through the regulation of several processes including the biogenesis of new mitochondria and mitochondria fusion/fission processes [192]. Although mitochondria biogenesis is regulated by several key factors including PPAR gamma coactivator-1 $\alpha$ (PGC-1 $\alpha$ ), Nrf1, Nrf2, and mitochondria transcription factor A (TFAM), direct inhibitors to these regulators have yet to be developed. Nevertheless, several drugs have been reported to show a direct impact on mitochondria biogenesis. 
TABLE 1: Summary of the various mitochondrial-related therapeutics in targeting tumor progression.

\begin{tabular}{|c|c|c|c|}
\hline Category & Drug name & Mechanism & References \\
\hline \multirow{3}{*}{ Complex I inhibitors } & Metformin & \multirow{3}{*}{$\begin{array}{l}\text { Inhibits complex I, disrupting ATP production } \\
\text { by OXPHOS. }\end{array}$} & {$[170]$} \\
\hline & IACS-010759 & & [171-173] \\
\hline & OPB-51602 & & {$[174,175]$} \\
\hline \multirow{2}{*}{ ATP synthase inhibitors } & Oligomycin & $\begin{array}{l}\text { Induces heightened superoxide production and } \\
\text { apoptosis in tumors. }\end{array}$ & {$[178,179]$} \\
\hline & Gboxin & $\begin{array}{l}\text { Restricts ATP synthase, increases mitochondria } \\
\text { membrane potential. }\end{array}$ & {$[180]$} \\
\hline \multirow[b]{2}{*}{$\begin{array}{l}\text { Mitochondria biogenesis } \\
\text { targeting compounds }\end{array}$} & Gamitinib & $\begin{array}{l}\text { Specifically inhibits tumor mitochondrial HSP90 } \\
\text { and induces mitochondria apoptosis. }\end{array}$ & [182-185] \\
\hline & Doxycycline & $\begin{array}{l}\text { Inhibits mitochondrial biogenesis in bacterial } \\
\text { and mammalian cells and reduces mitochondrial } \\
\text { translation. }\end{array}$ & {$[187,188]$} \\
\hline $\begin{array}{l}\text { Inhibitors of mitochondria } \\
\text { dynamics }\end{array}$ & $\begin{array}{l}\text { Mitochondrial division inhibitor } \\
\text { (e.g., Mdivi 1) }\end{array}$ & $\begin{array}{l}\text { Inhibits mitochondrial fission which prevents } \\
\text { cell cycle progression and hence suppresses } \\
\text { tumor growth. }\end{array}$ & [191-194] \\
\hline \multirow[t]{2}{*}{ SOD mimetics } & $\begin{array}{l}\text { Manganese porphyrins } \\
\text { (e.g., MnTnHex } 2 \text { PyP5+) }\end{array}$ & $\begin{array}{c}\text { Mimics MnSOD activity; increases cellular } \\
\text { ROS levels, and ultimately induces cell death. } \\
\text { Also inhibits cell } \\
\text { migration and invasion. }\end{array}$ & {$[198,199]$} \\
\hline & Nitroxides (e.g., Mito TEMPOL) & $\begin{array}{c}\text { Antioxidative function; induces DNA } \\
\text { damage, apoptosis, and mitochondrial distress } \\
\text { in tumors. }\end{array}$ & {$[200,201]$} \\
\hline \multirow[t]{2}{*}{ Bcl-2 inhibitors } & $\begin{array}{c}\text { ABT-263 (Navitoclax) } \\
\text { ABT-737 }\end{array}$ & $\begin{array}{l}\text { BH3 mimetic that targets antiapoptotic Bcl-2 } \\
\text { and Bcl-xL. }\end{array}$ & {$[206,207]$} \\
\hline & ABT-199 (Venetoclax) & BH3 mimetic that has affinity for antiapoptotic Bcl-2. & {$[209-213]$} \\
\hline
\end{tabular}
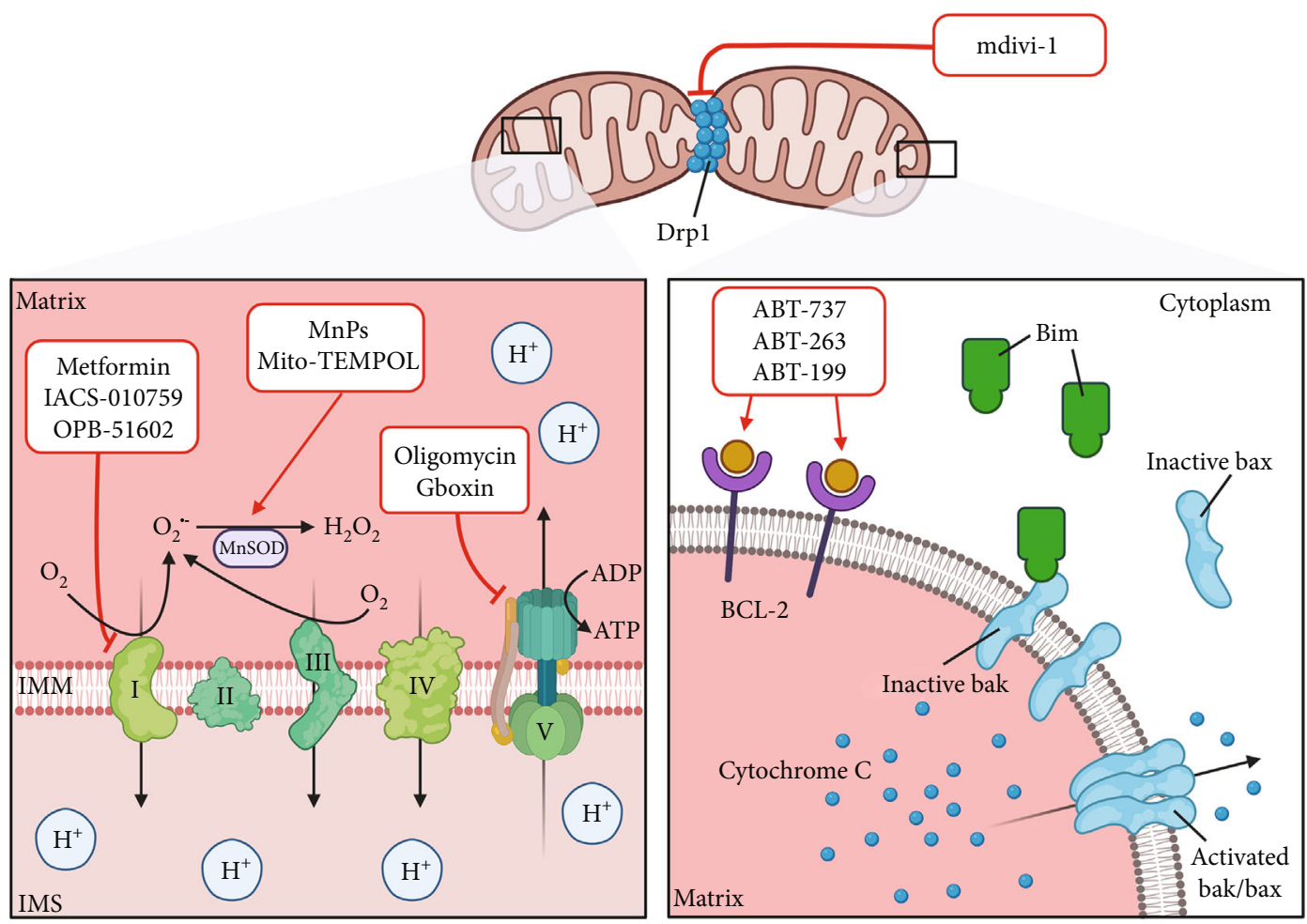

FIGURE 4: Mitochondrial-directed therapeutic strategies. For drugs that target the mitochondrial matrix, components of the electron transport chain and MnSOD are mainly affected, whereas drugs targeting cytosolic regulatory proteins/factors such as the balance between the pro- and antiapoptotic members of the Bcl-2 family affect apoptotic execution. Figure created with biorender.com. 
Gamitrinib is a small molecule mitochondrial HSP90 inhibitor that has shown promising antitumor effects in various cancer types including glioblastoma [193, 194] and prostate cancer [195]. Unlike other general HSP90 antagonists, gamitrinib selectively targets tumor mitochondria and does not affect the HSP90 homeostasis in other cellular compartments other than the mitochondria and does not induce toxicity to normal cells. Gamitrinib was observed to induce mitochondria apoptosis and a loss of inner membrane potential, which leads to the release of mitochondrial cytochrome c [196]. Gamitrinib has also been reported to lead to a decrease in mtDNA copy number, mitochondria mass, and respiration in melanoma cells, which is indicative of an inhibition of mitochondria biogenesis. Pretreatment with gamitrinib was able to sensitize vemurafenib-resistant A375 cells to vemurafenib treatment through inhibition of mitochondria biogenesis and activity [197].

Doxycycline is an FDA-approved antibiotic used in the treatment of various infections through targeting bacterial mitochondria. In cancer, doxycycline was observed to limit self-renewal ability of cancer stem cells (CSCs) in several types of cancers [198]. In addition to bacterial mitochondria, doxycycline was shown to inhibit mitochondrial biogenesis in mammalian cells; doxycycline treatment decreased mtDNA copy number and mitochondrial translation, eventually leading to cell death [199].

5.4. Inhibition of Mitochondria Dynamics. Mitochondria dynamics refer to the balance between fusion and fission that maintain mitochondria morphology and number in mammalian cells. Mitochondria fission is elevated under stress conditions, which induces mitochondrial fragmentation [200]. Impairment of mitochondria fusion and fission results in structural changes, cellular dysfunction, and damage [201]. Mitochondrial division inhibitor (mdivi-1) was reported to inhibit Drp1-dependent mitochondria fission and oxidative metabolism and impair cell proliferation in lung cancer [202]. Mdivi-1 was also reported to inhibit complex I function and modulate intracellular $\mathrm{Ca}^{2+}$ signaling [203]. The inhibition of mitochondria fission by mdivi-1 reduces tumor growth through prevention of cell cycle progression [204] and cell migration [205], suggesting mitochondrial dynamics as one of the targets and its inhibition as a way to suppress cancer cell growth.

5.5. SOD Mimetics. MnSOD (SOD2) is shown to be frequently dysregulated in several cancers, and thus, there is an emerging interest in complexes that mimic MnSOD (MnSOD mimetics) as therapeutic agents against cancers with suppressed MnSOD activity. SOD mimetics are modulators of cellular redox environment, and several compounds have been examined and reviewed in detail by Vincent et al., Batinic-Haberle et al., and Miriyala et al. [206-208]. In this section, we aim to evaluate the reported antitumor properties of some promising therapeutic MnSOD mimetics.

Manganese porphyrins $(\mathrm{MnP})$ are Mn-based SOD mimetics and have been identified as potential therapeutics due to their high SOD-like activity. In addition, MnP have been shown to regulate signaling pathways, which in turn modulate cellular processes such as apoptosis and proliferation. With excellent bioavailability and specificity for targeting mitochondria, MnTnHex-2-PyP ${ }^{5+}$ is considered one of the most promising therapeutic SOD mimics. Treatment with MnTnHex-2-PyP ${ }^{5+}$ increases cellular ROS levels and induces cell death in human renal cancer cells, 786-O [209]. Furthermore, MnTnHex-2- $\mathrm{PyP}^{5+}$ was shown to inhibit cell migration, chemotaxis, and invasion in doxorubicintreated breast cancer, demonstrating therapeutic potential in several cancer models [210]. Interestingly, another MnSOD mimic, MnTnBuOE-2-PyP ${ }^{5+}$ (MnBuOE/BMX-001) has been reported to enhance carbenoxolone- (CBX-) mediated tumor necrosis factor-related apoptosis-inducing ligand- (TRAIL-) induced apoptosis in GBM cells. MnBuOE also demonstrated an enhanced mitochondrial over cytosolic accumulation [211]. BMX-001 is currently in two Phase II studies-one in combination with radiation therapy and tamazolamide in glioblastoma and high-grade glioma and another in patients with multiple brain metastases (MBM) undergoing whole brain radiation therapy. In addition, the safety and tolerability of BMX-001 are currently being evaluated in two Phase I/II studies using a combination approach of BMX-001, standard radiation therapy (RT), and cisplatin in head and neck cancer patients to reduce radiation-induced mucositis and xerostomia, and in combination with 5-FU in anal squamous cell carcinoma (ASCC) (ClinicalTrials: NCT02655601, NCT02990468, NCT03386500, NCT03608020) [212].

Nitroxides are weak SOD mimetics which have been used as an antioxidant both in vivo and in vitro. MitoTEMPOL is a mitochondria-targeted derivative of TEMPOL, which catalyzes the dismutation of $\mathrm{O}_{2}{ }^{\bullet-}$ [213]. MitoTEMPOL possesses a triphenylphosphonium group which enhances its accumulation in the mitochondria. In a study by Dickey et al., Mito-TEMPOL treatment led to a reduction in tumor size as a single agent and enhanced the antitumor effect of doxorubicin in a murine syngeneic breast cancer model. Furthermore, Mito-TEMPOL was also observed to induce DNA damage, apoptosis, and mitochondrial distress in the tumors [214], highlighting its potential as a therapeutic antioxidant in cancer.

5.6. Bcl-2 Inhibitors. Antiapoptotic proteins like Bcl-2 are implicated in the intrinsic apoptotic pathway. The proteins prevent the oligomerization of effector Bax/Bak proteins into a membrane pore, disallowing the release of cytochrome $c$ [215] and modulate ROS production through regulation of mitochondria respiration $[128,216]$. Cytochrome $c$ is responsible for the activation of downstream caspase 3 and 8 which result in apoptosis [217]. BH3-only proteins (e.g., Bim, tBid, and PUMA) naturally induce apoptosis by inhibiting Bcl-2 proteins directly, facilitating MOMP for cytochrome c release [218]. The role that $\mathrm{Bcl}-2$ plays in apoptosis makes it an attractive drug target for novel inhibitors that aim to induce apoptosis in tumor cells. $\mathrm{BH} 3$ mimetics such as ABT-263 (Navitoclax) and ABT-737 targets both the main antiapoptotic proteins, $\mathrm{Bcl}-2$ and $\mathrm{Bcl}-\mathrm{xL}$ [219]. ABT-737 displayed antitumor potential in animal hematological cancer models, while a more stable ABT-263 
has been tested in phase I and II trials for human hematological cancers too [220].

However, thrombocytopenia is a significant toxicity that challenges the effectiveness of ABT-263 and ABT-737 [220, 221]. To combat this toxicity, a recently approved $\mathrm{BH} 3$ mimetic called ABT-199 (venetoclax) is proving to be specific for Bcl-2, possessing subnanomolecular affinity for Bcl-2, while not targeting Bcl-xL [222]. ABT-199 was shown to display a significant response rate in a phase I trial with CLL patients, with common side effects like diarrhea and neutropenia [223]. Phase II trials for ABT-199 on high-risk relapsed and refractory AML patients demonstrated promising clinical benefits with tolerable safety profile [224]. ABT199 was also effective in acute leukemia for both in vitro [225] and in vivo mouse studies [226]. BH3 mimetics displace $\mathrm{BH} 3$-only sensitizers such as Bim from binding with Bcl-2, directly inhibiting Bcl-2 and allowing free Bim to activate $\mathrm{Bax} / \mathrm{Bak}$ for cytochrome release $[227,228]$. However, a recent publication posits that $\mathrm{BH} 3$-only proteins can interact with $\mathrm{Bax} / \mathrm{Bak}$ but is not needed for apoptosis [229], which is consistent with an alternative $\mathrm{BH} 3$-only indirect activation model [230]. Although the exact mechanism for BH3 mimetics is unclear, the clinical benefits make them attractive antitumor mitochondrial therapies.

\section{Concluding Remarks}

A multitude of biological responses and signaling pathways impacted by altered cellular redox state is a testament to the crucial role that oxidative metabolism plays in cancer cell fate determination. Outstanding contributions over the past couple of decades have clearly highlighted the dichotomy of redox-mediated responses and their effect(s) on myriad processes associated with carcinogenesis and its progression, such as regulation of gene expression, genome instability and mutagenesis, structural and functional modifications of proteins, cell growth and proliferation, cell cycle progression, cellular senescence, and apoptosis execution and resistance. To that end, an intricate crosstalk between altered redox state (and mitochondrial metabolism) and oncogenic or tumor suppressor proteins has been elegantly demonstrated using various model systems. This has seen the emergence of a new paradigm in which cellular redox metabolism appears to dictate cancer cell fate decisions and as such a highly attractive target for novel anticancer drug design and development. The latter include therapeutics to specifically target mitochondrial metabolism, which is a potent source of intracellular ROS. Some of these strategies are already undergoing clinical evaluation such as the Mitocans and MnSOD mimetics. Despite these encouraging developments, there also remain important unresolved issues, such as the design of specific probes for the temporal and spatial detection in vivo of various reactive oxygen intermediates, the development of more effective oxidants/anti-oxidants with good therapeutic indices, and the selective delivery of mitochondria-targeted agents. Surely, the intricate interplay between mitochondria and cellular redox state in cancer cell fate is beginning to be realized and exploited for the design of ROS-targeted therapies.

\section{Abbreviations}

4-HNE: 4-Hydroxynonenal

8-oxo-dG: 8-Oxo-2' -deoxyguanosine

a-KG: Alpha-ketoglutarate

a-KGDH: Alpha ketoglutarate dehydrogenase

ADP: Adenosine diphosphate

Akt: $\quad$ Protein kinase B

ALCL: Anaplastic large cell lymphoma

ALL: $\quad$ Acute lymphocytic leukemia

AML: $\quad$ Acute myeloid leukemia

AMP: $\quad$ Adenosine monophosphate

AMPK: AMP-activated protein kinase

ANT: Adenine nucleotide translocase

ARE: Antioxidant response element

ASK-1: Apoptosis signal-regulating kinase 1

ATP: $\quad$ Adenosine triphosphate

Bak: $\quad$ BCL-2 associated X protein

Bax: $\quad$ BCL-2 homologous antagonist killer

BCL-2: B-cell lymphoma 2

BCL-XL: BCL- extra large

$\mathrm{Bcr} / \mathrm{Abl}$ Breakpoint cluster/Abelson

BH3: $\quad$ BCL-2 homology 3 region

Bim: BCL-2-like protein 11

CAFs: Cancer-associated fibroblasts

c-FLIP: CASP8 and FADD-like apoptosis regulator

CKI: Cyclin-dependent kinase inhibitor

CML: Chronic myelogenous leukemia

CoQ: $\quad$ Coenzyme Q

COX: Cyclooxygenase

DDR: DNA damage response

DNA: Deoxyribonucleic acid

dNTPs: Nucleoside triphosphate

ECM: $\quad$ Extracellular matrix

EGFR: Epidermal growth factor receptor

EMT: Epithelial-mesenchymal transition

ERK: Extracellular-signal regulated kinase

ETC: $\quad$ Electron transport chain

FAD: $\quad$ Flavin adenine dinucleotide

FADD: $\quad$ Fas-associated death domain protein

FasL: $\quad$ Fas ligand

FH: $\quad$ Fumarate hydratase

FMN: $\quad$ Flavin mononucleotide

GBM: Glioblastoma

GSH: $\quad$ Glutathione

GTPase: Guanosine trisphosphate hydrolase

HIF-1: Hypoxia-inducible factor 1

HMOX-1: Haem oxygenase 1

IKK: $\quad$ IkB kinase

IL-1: $\quad$ Interleukin 1

IL-6: Interleukin 6

IMS: Intermembrane space

JNK: c-Jun N-terminal kinase

Keap: $\quad$ Kelch-like ECH-associated protein 1

MAPK: Mitogen-activated protein kinase

MMPs: Matrix metalloproteases

MOMP: Mitochondrial outer membrane permeabilization

mPTP: Mitochondrial permeability transition pore

mTOR: Mammalian target of rapamycin 
NAD: Nicotinamide adenine dinucleotide

NADPH: Nicotinamide adenine dinucleotide phosphate hydrogen

NF-kB: Nuclear factor kappa-light-chain-enhancer of activated B cells

NOX: $\quad$ NAPH oxidase

Nrf2: $\quad$ Nuclear factor erythroid 2-related factor 2

NSCLC: Nonsmall cell lung cancer

OCT: Organic cation transporter

OIS: $\quad$ Oncogene-induced senescence

OXPHOS: Oxidative phosphorylation

PFK-1: $\quad$ Phosphofructokinase 1

PI3K: $\quad$ Phosphoinositide 3-kinase

$\mathrm{PIP}_{3}$ : $\quad$ Phosphatidylinositol $(3,4,5)$-triphosphate

PPP: $\quad$ Pentose phosphate pathway

PTEN: Phosphatase and tensin homolog

PUMA: $\quad$ 553 upregulated modulator of apoptosis

RNA: $\quad$ Ribonucleic acid

ROS: $\quad$ Reactive oxygen species

SASP: $\quad$ Senescence-associated secretory phenotype

SIPS: $\quad$ Stress-induced premature senescence

SOD: $\quad$ Superoxide dismutase

SUV: $\quad$ Suppressor of Var1

tBid: $\quad$ Truncated BH3-interacting domain death agonist

TCA: Tricarboxylic acid cycle

TIGAR: TP53-induced glycolysis and apoptosis regulator

TKI: $\quad$ Tyrosine kinase inhibitor

VDAC: Voltage-dependent anion channel

VEGF: Vascular endothelial growth factor.

\section{Data Availability}

It is a review paper and no data is included.

\section{Conflicts of Interest}

The authors declare that they have no conflicts of interest.

\section{Authors' Contributions}

Brittney Joy-Anne Foo and Jie Qing Eu contributed equally as first authors.

\section{Acknowledgments}

The authors wish to acknowledge the contributions of those whose work might have been inadvertently overlooked. Shazib Pervaiz (SP) is supported by the National Medical Research Council of Singapore (NMRC CIRG/1433/2015 and OFIRG/0041/2017), and a USPC-NUS 2021 award.

\section{References}

[1] L. Margulis and D. Sagan, Origins of Sex: Three Billion Years of Genetic Recombination, Yale University Press, 1990.

[2] L. Griparic and A. M. van der Bliek, "The many shapes of mitochondrial membranes," Traffic, vol. 2, no. 4, pp. 235244, 2001.
[3] S. Cardaci and M. R. Ciriolo, "TCA cycle defects and cancer: when metabolism tunes redox state," International Journal of Cell Biology, vol. 2012, Article ID 161837, 9 pages, 2012.

[4] M. W. van Gisbergen, A. M. Voets, M. H. Starmans et al., "How do changes in the mtDNA and mitochondrial dysfunction influence cancer and cancer therapy? Challenges, opportunities and models," Mutation Research/Reviews in Mutation Research, vol. 764, pp. 16-30, 2015.

[5] A. King, M. A. Selak, and E. Gottlieb, "Succinate dehydrogenase and fumarate hydratase : linking mitochondrial dysfunction and cancer," Oncogene, vol. 25, no. 34, pp. 4675$4682,2006$.

[6] J. F. Turrens, "Mitochondrial formation of reactive oxygen species," The Journal of physiology, vol. 552, no. 2, pp. 335344, 2003.

[7] U. Landmesser, D. G. Harrison, and H. Drexler, "Oxidant stress-a major cause of reduced endothelial nitric oxide availability in cardiovascular disease," European Journal of Clinical Pharmacology, vol. 62, no. S1, pp. 13-19, 2006.

[8] A. Panday, M. K. Sahoo, D. Osorio, and S. Batra, "NADPH oxidases: an overview from structure to innate immunityassociated pathologies," Cellular \& molecular immunology, vol. 12, no. 1, pp. 5-23, 2015.

[9] K. Bedard and K. H. Krause, "The NOX family of ROSgenerating NADPH oxidases: physiology and pathophysiology," Physiological reviews, vol. 87, no. 1, pp. 245-313, 2007.

[10] N. A. Graham, M. Tahmasian, B. Kohli et al., "Glucose deprivation activates a metabolic and signaling amplification loop leading to cell death," Molecular systems biology, vol. 8, no. 1, p. 589, 2012.

[11] T. Fukai and M. Ushio-Fukai, "Cross-talk between NADPH oxidase and mitochondria: role in ROS signaling and angiogenesis," Cells, vol. 9, no. 8, p. 1849, 2020.

[12] J. Smeitink, L. van den Heuvel, and S. DiMauro, "The genetics and pathology of oxidative phosphorylation," Nature Reviews Genetics, vol. 2, no. 5, pp. 342-352, 2001.

[13] L. Iommarini, M. A. Calvaruso, I. Kurelac, G. Gasparre, and A. M. Porcelli, "Complex I impairment in mitochondrial diseases and cancer: parallel roads leading to different outcomes," The international journal of biochemistry \& cell biology, vol. 45, no. 1, pp. 47-63, 2013.

[14] V. Raimondi, F. Ciccarese, and V. Ciminale, "Oncogenic pathways and the electron transport chain: a dangeROS liaison," British journal of cancer, vol. 122, no. 2, pp. 168-181, 2020.

[15] Y. Shang, F. Zhang, D. Li et al., "Overexpression of UQCRC2 is correlated with tumor progression and poor prognosis in colorectal cancer," Pathology-Research and Practice, vol. 214, no. 10, pp. 1613-1620, 2018.

[16] F. Gao, Q. Liu, G. Li et al., "Identification of ubiquinol cytochrome $\mathrm{c}$ reductase hinge (UQCRH) as a potential diagnostic biomarker for lung adenocarcinoma," Open biology, vol. 6, no. 6, 2016.

[17] D. E. Handy and J. Loscalzo, "Redox regulation of mitochondrial function," Antioxidants \& redox signaling, vol. 16, no. 11, pp. 1323-1367, 2012.

[18] M. Ogrunc, R. di Micco, M. Liontos et al., "Oncogeneinduced reactive oxygen species fuel hyperproliferation and DNA damage response activation," Cell Death \& Differentiation, vol. 21, no. 6, pp. 998-1012, 2014. 
[19] S. R. Lee, K. S. Yang, J. Kwon, C. Lee, W. Jeong, and S. G. Rhee, "Reversible Inactivation of the Tumor Suppressor PTEN by $\mathrm{H}_{2} \mathrm{O}_{2}$," Journal of Biological Chemistry, vol. 277, no. 23, pp. 20336-20342, 2002.

[20] B. Halliwell and S. Chirico, "Lipid peroxidation: its mechanism, measurement, and significance," The American journal of clinical nutrition, vol. 57, no. 5, pp. 715S-725S, 1993.

[21] S. P. LeDoux, W. J. Driggers, B. S. Hollensworth, and G. L. Wilson, "Repair of alkylation and oxidative damage in mitochondrial DNA," Mutation research. DNA repair, vol. 434, no. 3, pp. 149-159, 1999.

[22] J. Kwon, S. R. Lee, K. S. Yang et al., "Reversible oxidation and inactivation of the tumor suppressor PTEN in cells stimulated with peptide growth factors," Proceedings of the National Academy of Sciences, vol. 101, no. 47, pp. 1641916424, 2004.

[23] P. Gao, H. Zhang, R. Dinavahi et al., "HIF-dependent antitumorigenic effect of antioxidants in vivo," Cancer cell, vol. 12, no. 3, pp. 230-238, 2007.

[24] J. Richardson, K. A. Thomas, B. H. Rubin, and D. C. Richardson, "Crystal structure of bovine $\mathrm{Cu}, \mathrm{Zn}$ superoxide dismutase at 3 A resolution: chain tracing and metal ligands," Proceedings of the National Academy of Sciences, vol. 72, no. 4, pp. 1349-1353, 1975.

[25] J. A. Tainer, E. D. Getzoff, J. S. Richardson, and D. C. Richardson, "Structure and mechanism of copper, zinc superoxide dismutase," Nature, vol. 306, no. 5940, pp. 284-287, 1983.

[26] G. E. Borgstahl, H. E. Parge, M. J. Hickey, W. F. Beyer Jr., R. A. Hallewell, and J. A. Tainer, "The structure of human mitochondrial manganese superoxide dismutase reveals a novel tetrameric interface of two 4-helix bundles," Cell, vol. 71, no. 1, pp. 107-118, 1992.

[27] M. L. Teoh-Fitzgerald, M. P. Fitzgerald, T. J. Jensen, B. W. Futscher, and F. E. Domann, "Genetic and epigenetic inactivation of extracellular superoxide dismutase promotes an invasive phenotype in human lung cancer by disrupting ECM homeostasis," Molecular Cancer Research, vol. 10, no. 1, pp. 40-51, 2012.

[28] S. M. Tsai, M. F. Hou, S. H. Wu et al., "Expression of manganese superoxide dismutase in patients with breast cancer," The Kaohsiung journal of medical sciences, vol. 27, no. 5, pp. 167-172, 2011.

[29] A. Fu, S. Ma, N. Wei, B. X. Xuan Tan, E. Y. Tan, and K. Q. Luo, "High expression of MnSOD promotes survival of circulating breast cancer cells and increases their resistance to doxorubicin," Oncotarget, vol. 7, no. 31, pp. 50239-50257, 2016.

[30] Y. Hu, D. G. Rosen, Y. Zhou et al., "Mitochondrial Manganese-Superoxide Dismutase Expression in Ovarian Cancer:", Journal of Biological Chemistry, vol. 280, no. 47, pp. 39485-39492, 2005.

[31] A. P. Kumar, S. Y. Loo, S. W. Shin et al., "Manganese superoxide dismutase is a promising target for enhancing chemosensitivity of basal-like breast carcinoma," Antioxidants \& redox signaling, vol. 20, no. 15, pp. 2326-2346, 2014.

[32] S. Y. Loo, J. L. Hirpara, V. Pandey et al., "Manganese superoxide dismutase expression regulates the switch between an epithelial and a mesenchymal-like phenotype in breast carcinoma," Antioxidants \& redox signaling, vol. 25, no. 6, pp. 283-299, 2016.
[33] K. P. Bhabak and G. Mugesh, "Functional mimics of glutathione peroxidase: bioinspired synthetic antioxidants," Accounts of chemical research, vol. 43, no. 11, pp. 1408$1419,2010$.

[34] E. Jablonska, J. Gromadzinska, B. Peplonska et al., "Lipid peroxidation and glutathione peroxidase activity relationship in breast cancer depends on functional polymorphism of GPX1," BMC cancer, vol. 15, no. 1, p. 657, 2015.

[35] Z. Chen, T. Hu, S. Zhu, K. Mukaisho, W. El-Rifai, and D. F. Peng, "Glutathione peroxidase 7 suppresses cancer cell growth and is hypermethylated in gastric cancer," Oncotarget, vol. 8, no. 33, pp. 54345-54356, 2017.

[36] S. Y. Min, H. S. Kim, E. J. Jung, E. J. Jung, C. D. Jee, and W. H. Kim, "Prognostic significance of glutathione peroxidase 1 (GPX1) down-regulation and correlation with aberrant promoter methylation in human gastric cancer," Anticancer research, vol. 32, no. 8, pp. 3169-3175, 2012.

[37] A. Metere, F. Frezzotti, C. E. Graves et al., "A possible role for selenoprotein glutathione peroxidase (GPx1) and thioredoxin reductases (TrxR1) in thyroid cancer: our experience in thyroid surgery," Cancer cell international, vol. 18, no. 1, p. 7, 2018.

[38] S. Kumari, A. K. Badana, M. M. G, S. G, and R. Malla, "Reactive oxygen species: a key constituent in cancer survival," Biomarker insights, vol. 13, 2018.

[39] M. V. Clément and S. Pervaiz, "Intracellular superoxide and hydrogen peroxide concentrations: a critical balance that determines survival or death," Redox Report, vol. 6, no. 4, pp. 211-214, 2001.

[40] H. Yin, L. Xu, and N. A. Porter, "Free radical lipid peroxidation: mechanisms and analysis," Chemical reviews, vol. 111, no. 10, pp. 5944-5972, 2011.

[41] G. Brambilla, L. Sciabà, P. Faggin et al., "Cytotoxicity, DNA fragmentation and sister-chromatid exchange in Chinese hamster ovary cells exposed to the lipid peroxidation product 4-hydroxynonenal and homologous aldehydes," Mutation Research/Genetic Toxicology, vol. 171, no. 2-3, pp. 169-176, 1986.

[42] G. Barrera, R. Muraca, S. Pizzimenti et al., "Inhibition of cmyc expression induced by 4-hydroxynonenal, a product of lipid peroxidation, in the HL-60 human leukemic cell line," Biochemical and Biophysical Research Communications, vol. 203, no. 1, pp. 553-561, 1994.

[43] V. M. Fazio, G. Barrera, S. Martinotti et al., "4-Hydroxynonenal, a product of cellular lipid peroxidation, which modulates c- myc and globin gene expression in K562 erythroleukemic cells," Cancer Research, vol. 52, no. 18, pp. 4866-4871, 1992.

[44] S. Dalleau, M. Baradat, F. Gueraud, and L. Huc, "Cell death and diseases related to oxidative stress:4-hydroxynonenal (HNE) in the balance," Cell Death \& Differentiation, vol. 20, no. 12, pp. 1615-1630, 2013.

[45] E. Piskounova, M. Agathocleous, M. M. Murphy et al., "Oxidative stress inhibits distant metastasis by human melanoma cells," Nature, vol. 527, no. 7577, pp. 186-191, 2015.

[46] M. Redza-Dutordoir and D. A. Averill-Bates, "Activation of apoptosis signalling pathways by reactive oxygen species," Biochimica et Biophysica Acta (BBA)-Molecular Cell Research, vol. 1863, no. 12, pp. 2977-2992, 2016.

[47] K. Datta, P. Babbar, T. Srivastava, S. Sinha, and P. Chattopadhyay, "p53 dependent apoptosis in glioma cell 
lines in response to hydrogen peroxide induced oxidative stress," The international journal of biochemistry \& cell biology, vol. 34, no. 2, pp. 148-157, 2002.

[48] Y. Kitamura, T. Ota, Y. Matsuoka et al., "Hydrogen peroxideinduced apoptosis mediated by p53 protein in glial cells," Glia, vol. 25, no. 2, pp. 154-164, 1999.

[49] M. Cordani, G. Butera, R. Pacchiana et al., "Mutant p53associated molecular mechanisms of ROS regulation in cancer cells," Biomolecules, vol. 10, no. 3, p. 361, 2020.

[50] S. Macip, M. Igarashi, P. Berggren, J. Yu, S. W. Lee, and S. A. Aaronson, "Influence of induced reactive oxygen species in p53-mediated cell fate decisions," Molecular and cellular biology, vol. 23, no. 23, pp. 8576-8585, 2003.

[51] N. Y. L. Ngoi, A. Q. X. Liew, S. J. F. Chong, M. S. Davids, M.V. Clement, and S. Pervaiz, "The redox-senescence axis and its therapeutic targeting," Redox Biology, vol. 45, article 102032, 2021.

[52] G. Hewitt, D. Jurk, F. D. Marques et al., "Telomeres are favoured targets of a persistent DNA damage response in ageing and stress-induced senescence," Nature communications, vol. 3, no. 1, p. 708, 2012.

[53] J. F. Passos, G. Saretzki, S. Ahmed et al., "Mitochondrial dysfunction accounts for the stochastic heterogeneity in telomere-dependent senescence," PLoS biology, vol. 5, no. 5, article e110, 2007.

[54] Q. M. Chen, J. C. Bartholomew, J. Campisi, M. Acosta, J. D. Reagan, and B. N. Ames, "Molecular analysis of H2O2induced senescent-like growth arrest in normal human fibroblasts: p53 and Rb control G1 arrest but not cell replication," Biochemical Journal, vol. 332, no. 1, pp. 43-50, 1998.

[55] M. Serrano, A. W. Lin, M. E. McCurrach, D. Beach, and S. W. Lowe, "Oncogenic ras Provokes Premature Cell Senescence Associated with Accumulation of p53 and p16 ${ }^{\mathrm{INK} 4 \mathrm{a}}$," Cell, vol. 88, no. 5, pp. 593-602, 1997.

[56] P. Sun, N. Yoshizuka, L. New et al., "PRAK Is Essential for ras -Induced Senescence and Tumor Suppression," Cell, vol. 128, no. 2, pp. 295-308, 2007.

[57] Q. Deng, R. Liao, B. L. Wu, and P. Sun, "High Intensity ras Signaling Induces Premature Senescence by Activating p38 Pathway in Primary Human Fibroblasts," Journal of Biological Chemistry, vol. 279, no. 2, pp. 1050-1059, 2004.

[58] A. Takahashi, N. Ohtani, K. Yamakoshi et al., "Mitogenic signalling and the $\mathrm{p} 16^{\mathrm{INK} 4 \mathrm{a}}-\mathrm{Rb}$ pathway cooperate to enforce irreversible cellular senescence," Nature cell biology, vol. 8, no. 11, pp. 1291-1297, 2006.

[59] Q. Ma, "Role of nrf2 in oxidative stress and toxicity," Annual review of pharmacology and toxicology, vol. 53, no. 1, pp. 401426, 2013.

[60] G. M. DeNicola, F. A. Karreth, T. J. Humpton et al., "Oncogene-induced Nrf2 transcription promotes ROS detoxification and tumorigenesis," Nature, vol. 475, no. 7354, pp. 106-109, 2011.

[61] T. D. Oberley, W. Zhong, L. I. Szweda, and L. W. Oberley, "Localization of antioxidant enzymes and oxidative damage products in normal and malignant prostate epithelium," Prostate, vol. 44, no. 2, pp. 144-155, 2000.

[62] T. O. Khor, M. T. Huang, A. Prawan et al., "Increased susceptibility of Nrf2 knockout mice to colitis-associated colorectal cancer," Cancer prevention research, vol. 1, no. 3, pp. 187191, 2008.
[63] L. Becks, M. Prince, H. Burson et al., "Aggressive mammary carcinoma progression in Nrf2 knockout mice treated with 7,12-dimethylbenz[a] anthracene," BMC Cancer, vol. 10, no. 1, p. 540, 2010.

[64] K. Taguchi, H. Motohashi, and M. Yamamoto, "Molecular mechanisms of the Keap1-Nrf2 pathway in stress response and cancer evolution," Genes to cells, vol. 16, no. 2, pp. 123140, 2011.

[65] E. Kansanen, S. M. Kuosmanen, H. Leinonen, and A. L. Levonen, "The Keap1-Nrf2 pathway: mechanisms of activation and dysregulation in cancer," Redox biology, vol. 1, no. 1, pp. 45-49, 2013.

[66] I. S. Harris, A. E. Treloar, S. Inoue et al., "Glutathione and thioredoxin antioxidant pathways synergize to drive cancer initiation and progression," Cancer cell, vol. 27, no. 2, pp. 211222, 2015.

[67] D. B. Coursin, H. P. Cihla, J. Sempf, T. D. Oberley, and L. W. Oberley, "An immunohistochemical analysis of antioxidant and glutathione S-transferase enzyme levels in normal and neoplastic human lung," Histology and histopathology, vol. 11, no. 4, pp. 851-860, 1996.

[68] D. G. Bostwick, E. E. Alexander, R. Singh et al., "Antioxidant enzyme expression and reactive oxygen species damage in prostatic intraepithelial neoplasia and cancer," Cancer, vol. 89, no. 1, pp. 123-134, 2000.

[69] R. Kurzrock, H. M. Kantarjian, B. J. Druker, and M. Talpaz, "Philadelphia chromosome-positive leukemias: from basic mechanisms to molecular therapeutics," Annals of internal medicine, vol. 138, no. 10, pp. 819-830, 2003.

[70] S. Salesse and C. M. Verfaillie, "BCR/ABL: from molecular mechanisms of leukemia induction to treatment of chronic myelogenous leukemia," Oncogene, vol. 21, no. 56, pp. 8547-8559, 2002.

[71] D. Trachootham, Y. Zhou, H. Zhang et al., "Selective killing of oncogenically transformed cells through a ROS-mediated mechanism by $\beta$-phenylethyl isothiocyanate," Cancer Cell, vol. 10, no. 3, pp. 241-252, 2006.

[72] J. H. Kim, S. C. Chu, J. L. Gramlich et al., "Activation of the $\mathrm{PI} 3 \mathrm{~K} / \mathrm{mTOR}$ pathway by BCR-ABL contributes to increased production of reactive oxygen species," Blood, vol. 105, no. 4, pp. 1717-1723, 2005.

[73] M. Sattler, S. Verma, G. Shrikhande et al., "The BCR/ABL Tyrosine Kinase Induces Production of Reactive Oxygen Species in Hematopoietic Cells," Journal of Biological Chemistry, vol. 275, no. 32, pp. 24273-24278, 2000.

[74] M. Koptyra, R. Falinski, M. O. Nowicki et al., "BCR/ABL kinase induces self-mutagenesis via reactive oxygen species to encode imatinib resistance," Blood, vol. 108, no. 1, pp. 319-327, 2006.

[75] H. M. Amin and R. Lai, "Pathobiology of ALK+ anaplastic large-cell lymphoma,” Blood, vol. 110, no. 7, pp. 2259-2267, 2007.

[76] K. Thornber, A. Colomba, L. Ceccato, G. Delsol, B. Payrastre, and F. Gaits-Iacovoni, "Reactive oxygen species and lipoxygenases regulate the oncogenicity of NPM- ALK-positive anaplastic large cell lymphomas," Oncogene, vol. 28, no. 29, pp. 2690-2696, 2009.

[77] J. A. McCubrey, M. M. LaHair, and R. A. Franklin, "Reactive oxygen species-induced activation of the MAP kinase signaling pathways," Antioxidants \& redox signaling, vol. 8, no. 910, pp. 1775-1789, 2006. 
[78] D. Hanahan and R. A. Weinberg, "Hallmarks of cancer: the next generation," Cell, vol. 144, no. 5, pp. 646-674, 2011.

[79] H. Kasai and S. Nishimura, "Hydroxylation of deoxyguanosine at the C-8 position by ascorbic acid and other reducing agents," Nucleic acids research, vol. 12, no. 4, pp. 21372145, 1984.

[80] H. Kasai, P. F. Crain, Y. Kuchino, S. Nishimura, A. Ootsuyama, and H. Tanooka, "Formation of 8hydroxyguanine moiety in cellular DNA by agents producing oxygen radicals and evidence for its repair," Carcinogenesis, vol. 7, no. 11, pp. 1849-1851, 1986.

[81] C. J. Burrows and J. G. Muller, "Oxidative nucleobase modifications leading to strand scission," Chemical Reviews, vol. 98, no. 3, pp. 1109-1152, 1998.

[82] J. Cadet and J. R. Wagner, "DNA base damage by reactive oxygen species, oxidizing agents, and UV radiation," Cold Spring Harbor perspectives in biology, vol. 5, no. 2, 2013.

[83] R. A. Floyd, "Role of oxygen free radicals in carcinogenesis and brain ischemia," The FASEB journal, vol. 4, no. 9, pp. 2587-2597, 1990.

[84] T. Suzuki and H. Kamiya, "Mutations induced by 8hydroxyguanine (8-oxo-7,8-dihydroguanine), a representative oxidized base, in mammalian cells," Genes and Environment, vol. 39, no. 1, p. 2, 2017.

[85] H. Kamiya, N. Murata-Kamiya, S. Koizume, H. Inoue, S. Nishimura, and E. Ohtsuka, "8-Hydroxyguanine (7,8-dihydro-8-oxoguanine) in hot spots of the c-Ha-ras gene: effects of sequence contexts on mutation spectra," Carcinogenesis, vol. 16, no. 4, pp. 883-889, 1995.

[86] H. Kamiya, K. Miura, H. Ishikawa, H. Inoue, S. Nishimura, and E. Ohtsuka, "c-Ha-ras containing 8-hydroxyguanine at codon 12 induces point mutations at the modified and adjacent positions," Cancer research, vol. 52, no. 12, pp. 34833485, 1992.

[87] S. Borrego, A. Vazquez, F. Dasí et al., "Oxidative stress and DNA damage in human gastric carcinoma: 8-oxo-7'8-dihydro-2'-deoxyguanosine (8-oxo-dG) as a possible tumor marker," International Journal of Molecular Sciences, vol. 14, no. 2, pp. 3467-3486, 2013.

[88] M. Olivier, M. Hollstein, and P. Hainaut, “TP53 mutations in human cancers: origins, consequences, and clinical use," Cold Spring Harbor perspectives in biology, vol. 2, no. 1, article a001008, 2010.

[89] B. Vogelstein, D. Lane, and A. J. Levine, "Surfing the p53 network," Nature, vol. 408, no. 6810, pp. 307-310, 2000.

[90] C. Wanka, J. P. Steinbach, and J. Rieger, “Tp53-induced Glycolysis and Apoptosis Regulator (TIGAR) Protects Glioma Cells from Starvation-induced Cell Death by Up-regulating Respiration and Improving Cellular Redox Homeostasis," Journal of Biological Chemistry, vol. 287, no. 40, pp. 3343633446, 2012.

[91] A. A. Sablina, A. V. Budanov, G. V. Ilyinskaya, L. S. Agapova, J. E. Kravchenko, and P. M. Chumakov, "The antioxidant function of the p53 tumor suppressor," Nature medicine, vol. 11, no. 12, pp. 1306-1313, 2005.

[92] K. Bensaad, A. Tsuruta, M. A. Selak et al., "TIGAR, a p53inducible regulator of glycolysis and apoptosis," Cell, vol. 126, no. 1, pp. 107-120, 2006.

[93] R. Faraonio, P. Vergara, D. di Marzo et al., "p53 Suppresses the Nrf2-dependent Transcription of Antioxidant Response
Genes," Journal of Biological Chemistry, vol. 281, no. 52, pp. 39776-39784, 2006.

[94] P. Drane, A. Bravard, V. Bouvard, and E. May, "Reciprocal down-regulation of $p 53$ and SOD2 gene expression -implication in p53 mediated apoptosis," Oncogene, vol. 20, no. 4, pp. 430-439, 2001.

[95] U. S. Srinivas, B. W. Q. Tan, B. A. Vellayappan, and A. D. Jeyasekharan, "ROS and the DNA damage response in cancer," Redox biology, vol. 25, article 101084, 2019.

[96] K. Bensaad, E. C. Cheung, and K. H. Vousden, "Modulation of intracellular ROS levels by TIGAR controls autophagy," The EMBO journal, vol. 28, no. 19, pp. 3015-3026, 2009.

[97] A. Maillet and S. Pervaiz, "Redox regulation of p53, redox effectors regulated by p53: a subtle balance," Antioxidants \& redox signaling, vol. 16, no. 11, pp. 1285-1294, 2012.

[98] I. R. Indran, M. P. Hande, and S. Pervaiz, "hTERT overexpression alleviates intracellular ROS production, improves mitochondrial function, and inhibits ROS-mediated apoptosis in cancer cells," Cancer research, vol. 71, no. 1, pp. 266276, 2011.

[99] A. C. Newton, M. D. Bootman, and J. D. Scott, "Second messengers," Cold Spring Harbor perspectives in biology, vol. 8, no. $8,2016$.

[100] B. Chance, H. Sies, and A. Boveris, "Hydroperoxide metabolism in mammalian organs," Physiological reviews, vol. 59, no. 3, pp. 527-605, 1979.

[101] H. J. Forman, M. Maiorino, and F. Ursini, "Signaling functions of reactive oxygen species," Biochemistry, vol. 49, no. 5, pp. 835-842, 2010.

[102] H. Miki and Y. Funato, "Regulation of intracellular signalling through cysteine oxidation by reactive oxygen species," The Journal of Biochemistry, vol. 151, no. 3, pp. 255-261, 2012.

[103] H. E. Marshall, K. Merchant, and J. S. Stamler, "Nitrosation and oxidation in the regulation of gene expression," The FASEB Journal, vol. 14, no. 13, pp. 1889-1900, 2000.

[104] T. W. Poh and S. Pervaiz, "LY294002 and LY303511 sensitize tumor cells to drug-induced apoptosis via intracellular hydrogen peroxide production independent of the phosphoinositide 3-kinase-Akt pathway," Cancer research, vol. 65, no. 14, pp. 6264-6274, 2005.

[105] K. H. Kang, G. Lemke, and J. W. Kim, “The PI3K-PTEN tugof-war, oxidative stress and retinal degeneration," Trends in molecular medicine, vol. 15, no. 5, pp. 191-198, 2009.

[106] R. C. Kukreja, H. A. Kontos, M. L. Hess, and E. F. Ellis, "PGH synthase and lipoxygenase generate superoxide in the presence of NADH or NADPH," Circulation research, vol. 59, no. 6, pp. 612-619, 1986.

[107] A. Bhattacharyya, R. Chattopadhyay, S. Mitra, and S. E. Crowe, "Oxidative stress: an essential factor in the pathogenesis of gastrointestinal mucosal diseases," Physiological reviews, vol. 94, no. 2, pp. 329-354, 2014.

[108] S. Chatterjee, E. A. Browning, N. Hong et al., "Membrane depolarization is the trigger for PI3K/Akt activation and leads to the generation of ROS," American Journal of PhysiologyHeart and Circulatory Physiology, vol. 302, no. 1, pp. H105H114, 2012.

[109] J. Downward, "Targeting RAS signalling pathways in cancer therapy," Nature reviews cancer, vol. 3, no. 1, pp. 11-22, 2003.

[110] J. L. Meitzler, S. Antony, Y. Wu et al., "NADPH oxidases: a perspective on reactive oxygen species production in tumor 
biology," Antioxidants \& redox signaling, vol. 20, no. 17, pp. 2873-2889, 2014.

[111] Y. Samuels and T. Waldman, "Oncogenic mutations of PIK3CA in human cancers," Current Topics in Microbiology and Immunology, vol. 347, pp. 21-41, 2010.

[112] R. R. Madsen, B. Vanhaesebroeck, and R. K. Semple, "Cancer-Associated PIK3CA Mutations in Overgrowth Disorders," Trends in molecular medicine, vol. 24, no. 10, pp. 856-870, 2018.

[113] T. Shimoi, A. Hamada, M. Yamagishi et al., "PIK3CA mutation profiling in patients with breast cancer, using a highly sensitive detection system," Cancer science, vol. 109, no. 8, pp. 2558-2566, 2018.

[114] N. Ilic, K. Birsoy, A. J. Aguirre et al., "PIK3CA mutant tumors depend on oxoglutarate dehydrogenase," Proceedings of the National Academy of Sciences, vol. 114, no. 17, pp. E3434E3443, 2017.

[115] J. Ruffels, M. Griffin, and J. M. Dickenson, “Activation of ERK1/2, JNK and PKB by hydrogen peroxide in human SH-SY5Y neuroblastoma cells: role of ERK1/2 in $\mathrm{H}_{2} \mathrm{O}_{2}$ induced cell death," European journal of pharmacology, vol. 483, no. 2-3, pp. 163-173, 2004.

[116] C. H. Wong, K. B. Iskandar, S. K. Yadav, J. L. Hirpara, T. Loh, and S. Pervaiz, "Simultaneous induction of non-canonical autophagy and apoptosis in cancer cells by ROS-dependent ERK and JNK activation," PLoS One, vol. 5, no. 4, article e9996, 2010.

[117] H. Nagai, T. Noguchi, K. Takeda, and H. Ichijo, "Pathophysiological roles of ASK1-MAP kinase signaling pathways," BMB Reports, vol. 40, no. 1, pp. 1-6, 2007.

[118] Y. Hayakawa, Y. Hirata, H. Nakagawa et al., "Apoptosis signal-regulating kinase 1 and cyclin D1 compose a positive feedback loop contributing to tumor growth in gastric cancer," Proceedings of the National Academy of Sciences, vol. 108, no. 2, pp. 780-785, 2011.

[119] N. Kundu, S. Zhang, and A. M. Fulton, "Sublethal oxidative stress inhibits tumor cell adhesion and enhances experimental metastasis of murine mammary carcinoma," Clinical \& experimental metastasis, vol. 13, no. 1, pp. 1622, 1995.

[120] A. Belkhiri, C. Richards, M. Whaley, S. A. McQueen, and F. W. Orr, "Increased expression of activated matrix metalloproteinase-2 by human endothelial cells after sublethal H2O2 exposure," Laboratory investigation; a journal of technical methods and pathology, vol. 77, no. 5, pp. 533539, 1997.

[121] D. C. Radisky, D. D. Levy, L. E. Littlepage et al., "Raclb and reactive oxygen species mediate MMP-3-induced EMT and genomic instability," Nature, vol. 436, no. 7047, pp. 123127, 2005.

[122] D. S. Salomon, R. Brandt, F. Ciardiello, and N. Normanno, "Epidermal growth factor-related peptides and their receptors in human malignancies," Critical reviews in oncology/hematology, vol. 19, no. 3, pp. 183-232, 1995.

[123] K. Hyoudou, M. Nishikawa, Y. Kobayashi, Y. Umeyama, F. Yamashita, and M. Hashida, "PEGylated catalase prevents metastatic tumor growth aggravated by tumor removal," Free Radical Biology and Medicine, vol. 41, no. 9, pp. 1449-1458, 2006.

[124] L. F. Brown, M. Detmar, K. Claffey et al., "Vascular permeability factor/vascular endothelial growth factor: a multifunc- tional angiogenic cytokine," Regulation of angiogenesis, vol. 79, pp. 233-269, 1997.

[125] J. A. Bertout, S. A. Patel, and M. C. Simon, "The impact of $\mathrm{O}_{2}$ availability on human cancer," Nature Reviews Cancer, vol. 8, no. 12, pp. 967-975, 2008.

[126] P. Storz, H. Doppler, and A. Toker, "Protein kinase Cdelta selectively regulates protein kinase $\mathrm{D}$-dependent activation of NF-kappaB in oxidative stress signaling," Molecular and cellular biology, vol. 24, no. 7, pp. 2614-2626, 2004.

[127] Y. H. Yee, S. J. F. Chong, L. R. Kong, B. C. Goh, and S. Pervaiz, "Sustained IKK $\beta$ phosphorylation and NF- $\kappa$ B activation by superoxide-induced peroxynitrite-mediated nitrotyrosine modification of B56 33 and PP2A inactivation," Redox biology, vol. 41, article 101834, 2021.

[128] I. C. Low, Z. X. Chen, and S. Pervaiz, "Bcl-2 modulates resveratrol-induced ROS production by regulating mitochondrial respiration in tumor cells," Antioxidants \& redox signaling, vol. 13, no. 6, pp. 807-819, 2010.

[129] D. Raman, S. J. F. Chong, K. Iskandar, J. L. Hirpara, and S. Pervaiz, "Peroxynitrite promotes serine-62 phosphorylation-dependent stabilization of the oncoprotein c-Myc," Redox biology, vol. 34, article 101587, 2020.

[130] S. J. F. Chong, K. Iskandar, J. X. H. Lai et al., "Serine-70 phosphorylated $\mathrm{Bcl}-2$ prevents oxidative stress-induced DNA damage by modulating the mitochondrial redox metabolism," Nucleic acids research, vol. 48, no. 22, article 12727 , 45 pages, 2020.

[131] J. L. Hirpara, K. Subramaniam, G. Bellot et al., "Superoxide induced inhibition of death receptor signaling is mediated via induced expression of apoptosis inhibitory protein cFLIP," Redox biology, vol. 30, article 101403, 2020.

[132] S. Desagher, J. Glowinski, and J. Premont, "Pyruvate protects neurons against hydrogen peroxide-induced toxicity," Journal of Neuroscience, vol. 17, no. 23, pp. 9060-9067, 1997.

[133] D. Anastasiou, G. Poulogiannis, J. M. Asara et al., "Inhibition of pyruvate kinase $\mathrm{M} 2$ by reactive oxygen species contributes to cellular antioxidant responses," Science, vol. 334, no. 6060, pp. 1278-1283, 2011.

[134] G. A. Spoden, U. Rostek, S. Lechner, M. Mitterberger, S. Mazurek, and W. Zwerschke, "Pyruvate kinase isoenzyme M2 is a glycolytic sensor differentially regulating cell proliferation, cell size and apoptotic cell death dependent on glucose supply," Experimental cell research, vol. 315, no. 16, pp. 27652774, 2009.

[135] X. L. Zu and M. Guppy, "Cancer metabolism: facts, fantasy, and fiction," Biochemical and biophysical research communications, vol. 313, no. 3, pp. 459-465, 2004.

[136] S. Rodríguez-Enríquez, L. Carreño-Fuentes, J. C. GallardoPérez et al., "Oxidative phosphorylation is impaired by prolonged hypoxia in breast and possibly in cervix carcinoma," The international journal of biochemistry \& cell biology, vol. 42, no. 10, pp. 1744-1751, 2010.

[137] I. Hernández-Reséndiz, A. Román-Rosales, E. García-Villa et al., "Dual regulation of energy metabolism by p53 in human cervix and breast cancer cells," Biochimica et Biophysica Acta (BBA)-Molecular Cell Research, vol. 1853, no. 12, pp. 3266-3278, 2015.

[138] G. Migneco, D. Whitaker-Menezes, B. Chiavarina et al., "Glycolytic cancer associated fibroblasts promote breast cancer tumor growth, without a measurable increase in 
angiogenesis: evidence for stromal-epithelial metabolic coupling," Cell Cycle, vol. 9, no. 12, pp. 2412-2422, 2010.

[139] A. Orimo, P. B. Gupta, D. C. Sgroi et al., "Stromal fibroblasts present in invasive human breast carcinomas promote tumor growth and angiogenesis through elevated SDF-1/CXCL12 secretion," Cell, vol. 121, no. 3, pp. 335-348, 2005.

[140] S. Pavlides, D. Whitaker-Menezes, R. Castello-Cros et al., "The reverse Warburg effect: aerobic glycolysis in cancer associated fibroblasts and the tumor stroma," Cell Cycle, vol. 8, no. 23, pp. 3984-4001, 2009.

[141] A. Pastò, C. Bellio, G. Pilotto et al., "Cancer stem cells from epithelial ovarian cancer patients privilege oxidative phosphorylation, and resist glucose deprivation," Oncotarget, vol. 5, no. 12, pp. 4305-4319, 2014.

[142] V. de Rosa, F. Iommelli, M. Monti et al., "Reversal of Warburg effect and reactivation of oxidative phosphorylation by differential inhibition of EGFR signaling pathways in nonsmall cell lung cancer," Clinical Cancer Research, vol. 21, no. 22 , pp. 5110-5120, 2015.

[143] J. Hirpara, J. Q. Eu, J. K. M. Tan et al., "Metabolic reprogramming of oncogene-addicted cancer cells to OXPHOS as a mechanism of drug resistance," Redox biology, vol. 25, article 101076, 2019.

[144] D. S. Matassa, M. R. Amoroso, H. Lu et al., "Oxidative metabolism drives inflammation-induced platinum resistance in human ovarian cancer," Cell Death \& Differentiation, vol. 23, no. 9, pp. 1542-1554, 2016.

[145] A. C. Nulton-Persson and L. I. Szweda, "Modulation of Mitochondrial Function by Hydrogen Peroxide," Journal of Biological Chemistry, vol. 276, no. 26, pp. 23357-23361, 2001.

[146] B. E. Baysal, R. E. Ferrell, J. E. Willett-Brozick et al., "Mutations in SDHD, a mitochondrial complex II gene, in hereditary paraganglioma," Science, vol. 287 , no. 5454 , pp. $848-$ $851,2000$.

[147] S. Niemann and U. Muller, "Mutations in SDHC cause autosomal dominant paraganglioma, type 3," Nature genetics, vol. 26, no. 3, pp. 268-270, 2000.

[148] K. Hadrava Vanova, M. Kraus, J. Neuzil, and J. Rohlena, "Mitochondrial complex II and reactive oxygen species in disease and therapy," Redox Report, vol. 25, no. 1, pp. 26$32,2020$.

[149] C. Bardella, P. J. Pollard, and I. Tomlinson, "SDH mutations in cancer," Biochimica et Biophysica Acta (BBA)-Bioenergetics, vol. 1807, no. 11, pp. 1432-1443, 2011.

[150] S. Picaud, K. L. Kavanagh, W. W. Yue et al., "Structural basis of fumarate hydratase deficiency," Journal of inherited metabolic disease, vol. 34, no. 3, pp. 671-676, 2011.

[151] R. Lehtonen, M. Kiuru, S. Vanharanta et al., "Biallelic Inactivation of Fumarate Hydratase (FH) Occurs in Nonsyndromic Uterine Leiomyomas but Is Rare in Other Tumors," The American journal of pathology, vol. 164, no. 1, pp. 17-22, 2004.

[152] I. P. Tomlinson, N. A. Alam, A. J. Rowan et al., "Germline mutations in $\mathrm{FH}$ predispose to dominantly inherited uterine fibroids, skin leiomyomata and papillary renal cell cancer," Nature genetics, vol. 30, no. 4, pp. 406-410, 2002.

[153] J. Adam, E. Hatipoglu, L. O'Flaherty et al., "Renal cyst formation in Fh1-deficient mice is independent of the Hif/Phd pathway: roles for fumarate in KEAP1 succination and Nrf2 signaling," Cancer Cell, vol. 20, no. 4, pp. 524537, 2011.
[154] M. Escoll, D. Lastra, M. Pajares et al., "Transcription factor NRF2 uses the Hippo pathway effector TAZ to induce tumorigenesis in glioblastomas," Redox Biology, vol. 30, article 101425, 2020.

[155] C. Frezza, L. Zheng, O. Folger et al., "Haem oxygenase is synthetically lethal with the tumour suppressor fumarate hydratase," Nature, vol. 477, no. 7363, pp. 225-228, 2011.

[156] P. L. Chen, C. F. Chen, Y. Chen et al., "Mitochondrial genome instability resulting from SUV3 haploinsufficiency leads to tumorigenesis and shortened lifespan," Oncogene, vol. 32, no. 9, pp. 1193-1201, 2013.

[157] L. Khidr, G. Wu, A. Davila, V. Procaccio, D. Wallace, and W. H. Lee, "Role of SUV3 Helicase in Maintaining Mitochondrial Homeostasis in Human Cells," Journal of Biological Chemistry, vol. 283, no. 40, pp. 27064-27073, 2008.

[158] M. Alexeyev, I. Shokolenko, G. Wilson, and S. LeDoux, "The maintenance of mitochondrial DNA integrity-critical analysis and update," Cold Spring Harbor perspectives in biology, vol. 5, no. 5, article a012641, 2013.

[159] S. Anderson, A. T. Bankier, B. G. Barrell et al., "Sequence and organization of the human mitochondrial genome," Nature, vol. 290, no. 5806, pp. 457-465, 1981.

[160] A. Chatterjee, E. Mambo, and D. Sidransky, "Mitochondrial DNA mutations in human cancer," Oncogene, vol. 25, no. 34, pp. 4663-4674, 2006.

[161] A. S. Sun, K. Sepkowitz, and S. A. Geller, "A study of some mitochondrial and peroxisomal enzymes in human colonic adenocarcinoma," Laboratory investigation; a journal of technical methods and pathology, vol. 44, no. 1, pp. 13-17, 1981.

[162] B. G. Heerdt, H. K. Halsey, M. Lipkin, and L. H. Augenlicht, "Expression of mitochondrial cytochrome $\mathrm{c}$ oxidase in human colonic cell differentiation, transformation, and risk for colonic cancer," Cancer research, vol. 50, no. 5, pp. 1596-1600, 1990.

[163] A. S. Sun and A. I. Cederbaum, "Oxidoreductase activities in normal rat liver, tumor-bearing rat liver, and hepatoma HC252," Cancer Research, vol. 40, no. 12, pp. 4677-4681, 1980.

[164] S. Dasgupta, M. O. Hoque, S. Upadhyay, and D. Sidransky, "Mitochondrial cytochrome B gene mutation promotes tumor growth in bladder cancer," Cancer research, vol. 68, no. 3, pp. 700-706, 2008.

[165] L. Iommarini, I. Kurelac, M. Capristo et al., "Different mtDNA mutations modify tumor progression in dependence of the degree of respiratory complex I impairment," Human molecular genetics, vol. 23, no. 6, pp. 1453-1466, 2014.

[166] A. Dautant, T. Meier, A. Hahn, D. Tribouillard-Tanvier, J. P. di Rago, and R. Kucharczyk, "ATP synthase diseases of mitochondrial genetic origin," Frontiers in physiology, vol. 9, p. 329, 2018.

[167] L. Grzybowska-Szatkowska, B. Slaska, J. Rzymowska, A. Brzozowska, and B. Florianczyk, "Novel mitochondrial mutations in the ATP6 and ATP8 genes in patients with breast cancer," Molecular medicine reports, vol. 10, no. 4, pp. 1772-1778, 2014.

[168] M. Singh, H. Sharma, and N. Singh, "Hydrogen peroxide induces apoptosis in HeLa cells through mitochondrial pathway," Mitochondrion, vol. 7, no. 6, pp. 367-373, 2007.

[169] K. A. Ahmad, K. B. Iskandar, J. L. Hirpara, M. V. Clement, and S. Pervaiz, "Hydrogen peroxide-mediated cytosolic acidification is a signal for mitochondrial translocation of Bax 
during drug-induced apoptosis of tumor cells," Cancer research, vol. 64, no. 21, pp. 7867-7878, 2004.

[170] M. V. Clement, A. Ponton, and S. Pervaiz, "Apoptosis induced by hydrogen peroxide is mediated by decreased superoxide anion concentration and reduction of intracellular milieu," FEBS letters, vol. 440, no. 1-2, pp. 13-18, 1998.

[171] S. Teramoto, T. Tomita, H. Matsui, E. Ohga, T. Matsuse, and Y. Ouchi, "Hydrogen peroxide-induced apoptosis and necrosis in human lung fibroblasts: protective roles of glutathione," The Japanese Journal of Pharmacology, vol. 79, no. 1, pp. 3340, 1999.

[172] Y. J. Lee and E. Shacter, "Hydrogen peroxide inhibits activation, not activity, of cellular caspase-3 in vivo," Free Radical Biology and Medicine, vol. 29, no. 7, pp. 684-692, 2000.

[173] Y. J. Lee and E. Shacter, "Oxidative Stress Inhibits Apoptosis in Human Lymphoma Cells," Journal of Biological Chemistry, vol. 274, no. 28, pp. 19792-19798, 1999.

[174] M. L. Circu and T. Y. Aw, "Glutathione and modulation of cell apoptosis," Biochimica et Biophysica Acta (BBA)-Molecular Cell Research, vol. 1823, no. 10, pp. 1767-1777, 2012.

[175] M. L. Circu and T. Y. Aw, "Reactive oxygen species, cellular redox systems, and apoptosis," Free Radical Biology and Medicine, vol. 48, no. 6, pp. 749-762, 2010.

[176] P. Pallepati and D. Averill-Bates, "Mild thermotolerance induced at $40{ }^{\circ} \mathrm{C}$ increases antioxidants and protects HeLa cells against mitochondrial apoptosis induced by hydrogen peroxide: Role of p53," Archives of biochemistry and biophysics, vol. 495, no. 2, pp. 97-111, 2010.

[177] M. V. Clément, J. L. Hirpara, and S. Pervaiz, "Decrease in intracellular superoxide sensitizes Bcl-2-overexpressing tumor cells to receptor and drug-induced apoptosis independent of the mitochondria," Cell Death \& Differentiation, vol. 10, no. 11, pp. 1273-1285, 2003.

[178] M. Pollak, “The insulin and insulin-like growth factor receptor family in neoplasia: an update," Nature Reviews Cancer, vol. 12, no. 3, pp. 159-169, 2012.

[179] K. Marycz, K. A. Tomaszewski, K. Kornicka et al., "Metformin decreases reactive oxygen species, enhances osteogenic properties of adipose-derived multipotent mesenchymal stem cells in vitro, and increases bone density in vivo," Oxidative medicine and cellular longevity, vol. 2016, Article ID 9785890, 19 pages, 2016.

[180] J. R. Molina, Y. Sun, M. Protopopova et al., "An inhibitor of oxidative phosphorylation exploits cancer vulnerability," Nature medicine, vol. 24, no. 7, pp. 1036-1046, 2018.

[181] H. V. Vangapandu, B. Alston, J. Morse et al., "Biological and metabolic effects of IACS-010759, an OxPhos inhibitor, on chronic lymphocytic leukemia cells," Oncotarget, vol. 9, no. 38, pp. 24980-24991, 2018.

[182] T. A. Yap, J. Rodon Ahnert, S. A. Piha-Paul et al., "Phase I trial of IACS-010759 (IACS), a potent, selective inhibitor of complex I of the mitochondrial electron transport chain, in patients (pts) with advanced solid tumors," Journal of Clinical Oncology, vol. 37, 15 supplement, p. 3014, 2019.

[183] S. B. Panina, J. Pei, N. Baran, M. Konopleva, and N. V. Kirienko, "Utilizing synergistic potential of mitochondriatargeting drugs for leukemia therapy," Frontiers in oncology, vol. 10, p. 435, 2020.

[184] Q. Zhang, A. Lodi, S. R. Sweeney et al., "Inhibiting mitochondria function by $\mathrm{Bcl}-2$ inhibitor venetoclax and complex I inhibitor Iacs-010759 eliminate leukemia cells in pre- clinical AML models," Blood, vol. 134, Supplement_1, p. 3927, 2019.

[185] D. Chen, H. B. Barsoumian, G. Fischer et al., "Combination treatment with radiotherapy and a novel oxidative phosphorylation inhibitor overcomes PD-1 resistance and enhances antitumor immunity," Journal for immunotherapy of cancer, vol. 8, no. 1, article e000289, 2020.

[186] A. L. Wong, R. A. Soo, D. S. Tan et al., "Phase I and biomarker study of OPB-51602, a novel signal transducer and activator of transcription (STAT) 3 inhibitor, in patients with refractory solid malignancies," Annals of Oncology, vol. 26, no. 5, pp. 998-1005, 2015.

[187] D. Genini, L. Brambilla, E. Laurini et al., "Mitochondrial dysfunction induced by a SH2 domain-targeting STAT3 inhibitor leads to metabolic synthetic lethality in cancer cells," Proceedings of the National Academy of Sciences, vol. 114, no. 25, pp. E4924-E4933, 2017.

[188] F. Huijing and E. C. Slater, "The use of oligomycin as an inhibitor of oxidative phosphorylation," The Journal of Biochemistry, vol. 49, no. 6, pp. 493-501, 1961.

[189] D. S. Perlin, L. R. Latchney, and A. E. Senior, "Inhibition of Escherichia coli $\mathrm{H}^{+}$-ATPase by venturicidin, oligomycin and ossamycin," Biochimica et Biophysica Acta (BBA)-Bioenergetics, vol. 807, no. 3, pp. 238-244, 1985.

[190] F. Alvarez-Calderon, M. A. Gregory, C. Pham-Danis et al., "Tyrosine kinase inhibition in leukemia induces an altered metabolic state sensitive to mitochondrial perturbations," Clinical Cancer Research, vol. 21, no. 6, pp. 1360-1372, 2015.

[191] Y. Shi, S. K. Lim, Q. Liang et al., "Gboxin is an oxidative phosphorylation inhibitor that targets glioblastoma," Nature, vol. 567, no. 7748, pp. 341-346, 2019.

[192] R. M. Whitaker, D. Corum, C. C. Beeson, and R. G. Schnellmann, "Mitochondrial biogenesis as a pharmacological target: a new approach to acute and chronic diseases," Annual review of pharmacology and toxicology, vol. 56, no. 1, pp. 229-249, 2016.

[193] M. D. Siegelin, T. Dohi, C. M. Raskett et al., "Exploiting the mitochondrial unfolded protein response for cancer therapy in mice and human cells," The Journal of clinical investigation, vol. 121, no. 4, pp. 1349-1360, 2011.

[194] J. C. Ghosh, M. D. Siegelin, V. Vaira et al., "Adaptive mitochondrial reprogramming and resistance to PI3K therapy," JNCI: Journal of the National Cancer Institute, vol. 107, no. 3, 2015.

[195] B. H. Kang, M. D. Siegelin, J. Plescia et al., "Preclinical characterization of mitochondria-targeted small molecule hsp90 inhibitors, gamitrinibs, in advanced prostate cancer," Clinical Cancer Research, vol. 16, no. 19, pp. 4779-4788, 2010.

[196] B. H. Kang, J. Plescia, H. Y. Song et al., "Combinatorial drug design targeting multiple cancer signaling networks controlled by mitochondrial Hsp90," The Journal of clinical investigation, vol. 119, no. 3, pp. 454-464, 2009.

[197] G. Zhang, D. T. Frederick, L. Wu et al., "Targeting mitochondrial biogenesis to overcome drug resistance to MAPK inhibitors," The Journal of clinical investigation, vol. 126, no. 5, pp. 1834-1856, 2016.

[198] C. C. Lin, M. C. Lo, R. R. Moody, N. O. Stevers, S. L. Tinsley, and D. Sun, "Doxycycline targets aldehyde dehydrogenase-positive breast cancer stem cells," Oncology reports, vol. 39, no. 6, pp. 3041-3047, 2018. 
[199] S. N. Dijk, M. Protasoni, M. Elpidorou, A. M. Kroon, and J.W. Taanman, "Mitochondria as target to inhibit proliferation and induce apoptosis of cancer cells: the effects of doxycycline and gemcitabine," Scientific Reports, vol. 10, no. 1, p. $4363,2020$.

[200] S. Iqbal and D. A. Hood, "Oxidative stress-induced mitochondrial fragmentation and movement in skeletal muscle myoblasts," American Journal of Physiology-Cell Physiology, vol. 306, no. 12, pp. C1176-C1183, 2014.

[201] P. H. Reddy, "Inhibitors of mitochondrial fission as a therapeutic strategy for diseases with oxidative stress and mitochondrial dysfunction," Journal of Alzheimer's Disease, vol. 40, no. 2, pp. 245-256, 2014.

[202] W. Dai, G. Wang, J. Chwa et al., "Mitochondrial division inhibitor (mdivi-1) decreases oxidative metabolism in cancer," British journal of cancer, vol. 122, no. 9, pp. 12881297,2020

[203] C. Duan, L. Wang, J. Zhang et al., "Mdivi-1 attenuates oxidative stress and exerts vascular protection in ischemic/hypoxic injury by a mechanism independent of Drp1 GTPase activity," Redox biology, vol. 37, article 101706, 2020.

[204] J. Rehman, H. J. Zhang, P. T. Toth et al., "Inhibition of mitochondrial fission prevents cell cycle progression in lung cancer," The FASEB Journal, vol. 26, no. 5, pp. 2175-2186, 2012.

[205] A. Ferreira-da-Silva, C. Valacca, E. Rios et al., "Mitochondrial dynamics protein Drp1 is overexpressed in oncocytic thyroid tumors and regulates cancer cell migration," PLoS One, vol. 10, no. 3, article e0122308, 2015.

[206] A. Vincent, M. Thauvin, E. Quévrain et al., "Evaluation of the compounds commonly known as superoxide dismutase and catalase mimics in cellular models," Journal of inorganic biochemistry, vol. 219, article 111431, 2021.

[207] S. Miriyala, I. Spasojevic, A. Tovmasyan et al., "Manganese superoxide dismutase, MnSOD and its mimics," Biochimica et Biophysica Acta (BBA)-Molecular Basis of Disease, vol. 1822, no. 5, pp. 794-814, 2012.

[208] I. Batinic-Haberle, A. Tovmasyan, E. R. H. Roberts, Z. Vujaskovic, K. W. Leong, and I. Spasojevic, "SOD therapeutics: latest insights into their structure-activity relationships and impact on the cellular redox-based signaling pathways," Antioxidants \& redox signaling, vol. 20, no. 15, pp. 2372-2415, 2014.

[209] J. G. Costa, N. Saraiva, I. Batinic-Haberle, M. Castro, N. G. Oliveira, and A. S. Fernandes, "The SOD Mimic MnTnHex$2-\mathrm{PyP}^{5+}$ reduces the viability and migration of 786-O human renal cancer cells," Antioxidants (Basel), vol. 8, no. 10, p. 490, 2019.

[210] A. Flórido, N. Saraiva, S. Cerqueira et al., "The manganese(III) porphyrin $\mathrm{MnTnHex}-2-\mathrm{PyP}^{5+}$ modulates intracellular ROS and breast cancer cell migration: Impact on doxorubicin- treated cells," Redox biology, vol. 20, pp. 367378, 2019.

[211] Y. Yulyana, A. Tovmasyan, I. A. W. Ho et al., "Redox-active Mn porphyrin-based potent SOD mimic, MnTnBuOE-2$\mathrm{Py}^{5+}$, enhances carbenoxolone-mediated TRAIL-induced apoptosis in glioblastoma multiforme," Stem cell reviews and reports, vol. 12, no. 1, pp. 140-155, 2016.

[212] S. L. Schlichte, E. J. Pekas, T. J. Bruett et al., "Sympathoinhibition and vasodilation contribute to the acute hypotensive response of the superoxide dismutase mimic, MnTnBuOE-
2-PyP $\mathrm{P}^{5+}$, in hypertensive animals," Advances in Redox Research, vol. 3, article 100016, 2021.

[213] J. Trnka, F. H. Blaikie, A. Logan, R. A. Smith, and M. P. Murphy, "Antioxidant properties of MitoTEMPOL and its hydroxylamine," Free radical research, vol. 43, no. 1, pp. 412, 2009.

[214] J. S. Dickey, Y. Gonzalez, B. Aryal et al., "Mito-tempol and dexrazoxane exhibit cardioprotective and chemotherapeutic effects through specific protein oxidation and autophagy in a syngeneic breast tumor preclinical model," PloS one, vol. 8, no. 8, article e70575, 2013.

[215] J. E. Chipuk and D. R. Green, "How do BCL-2 proteins induce mitochondrial outer membrane permeabilization?" Trends in cell biology, vol. 18, no. 4, pp. 157-164, 2008.

[216] Z. X. Chen and S. Pervaiz, "Bcl-2 induces pro-oxidant state by engaging mitochondrial respiration in tumor cells," Cell Death \& Differentiation, vol. 14, no. 9, pp. 1617-1627, 2007.

[217] X. Jiang and X. Wang, "CytochromeC-Mediated apoptosis," Annual review of biochemistry, vol. 73, no. 1, pp. 87-106, 2004.

[218] R. J. Youle and A. Strasser, "The BCL-2 protein family: opposing activities that mediate cell death," Nature reviews Molecular cell biology, vol. 9, no. 1, pp. 47-59, 2008.

[219] C. M. Park, M. Bruncko, J. Adickes et al., "Discovery of an orally bioavailable small molecule inhibitor of prosurvival B-cell lymphoma 2 proteins," Journal of medicinal chemistry, vol. 51, no. 21, pp. 6902-6915, 2008.

[220] G. Wierda, P. Roberts, R. Brown et al., "Pharmacokinetics, safety and anti-tumor activity of ABT-263 in patients with relapsed or refractory chronic lymphocytic leukemia/small lymphocytic lymphoma," Haematologica-The Hematology Journal, vol. 94, p. 138, 2009.

[221] K. D. Mason, M. R. Carpinelli, J. I. Fletcher et al., "Programmed anuclear cell death delimits platelet life span," Cell, vol. 128, no. 6, pp. 1173-1186, 2007.

[222] A. J. Souers, J. D. Leverson, E. R. Boghaert et al., "ABT-199, a potent and selective BCL-2 inhibitor, achieves antitumor activity while sparing platelets," Nature medicine, vol. 19, no. 2, pp. 202-208, 2013.

[223] J. F. Seymour, M. S. Davids, J. M. Pagel et al., "ABT-199 (GDC-0199) in relapsed/refractory (R/R) chronic lymphocytic leukemia (CLL) and small lymphocytic lymphoma (SLL): High complete-response rate and durable disease control," American Society of Clinical Oncology, vol. 32, 15 supplement, p. 7015, 2014.

[224] M. Konopleva, D. A. Pollyea, J. Potluri et al., “A phase 2 study of ABT-199 (GDC-0199) in patients with acute myelogenous leukemia (AML)," Blood, vol. 124, no. 21, p. 118, 2014.

[225] R. Pan, L. J. Hogdal, J. M. Benito et al., "Selective BCL-2 inhibition by ABT-199 causes on-target cell death in acute myeloid leukemia," Cancer discovery, vol. 4, no. 3, pp. 362-375, 2014.

[226] S. Peirs, F. Matthijssens, S. Goossens et al., "ABT-199 mediated inhibition of BCL-2 as a novel therapeutic strategy in T-cell acute lymphoblastic leukemia," Blood, vol. 124, no. 25 , pp. 3738-3747, 2014.

[227] J. F. Lovell, L. P. Billen, S. Bindner et al., "Membrane binding by tBid initiates an ordered series of events culminating in membrane permeabilization by Bax," Cell, vol. 135, no. 6, pp. 1074-1084, 2009. 
[228] P. E. Czabotar, D. Westphal, G. Dewson et al., "Bax crystal structures reveal how $\mathrm{BH} 3$ domains activate $\mathrm{Bax}$ and nucleate its oligomerization to induce apoptosis," Cell, vol. 152, no. 3, pp. 519-531, 2013.

[229] K. Huang, K. L. O’Neill, J. Li et al., “BH3-only proteins target BCL-xL/MCL-1, not BAX/BAK, to initiate apoptosis," Cell research, vol. 29, no. 11, pp. 942-952, 2019.

[230] S. N. Willis, J. I. Fletcher, T. Kaufmann et al., "Apoptosis initiated when $\mathrm{BH} 3$ ligands engage multiple $\mathrm{Bcl}-2$ homologs, not Bax or Bak," Science, vol. 315, no. 5813, pp. 856-859, 2007. 